Portland State University

PDXScholar

\title{
Blockmodeling Network Data From Six Small Towns: an Assessment of Organizational Typologies
}

Peter J. Collier

Portland State University

Follow this and additional works at: https://pdxscholar.library.pdx.edu/open_access_etds

Part of the Work, Economy and Organizations Commons Let us know how access to this document benefits you.

\section{Recommended Citation}

Collier, Peter J., "Blockmodeling Network Data From Six Small Towns: an Assessment of Organizational Typologies" (1989). Dissertations and Theses. Paper 3892.

https://doi.org/10.15760/etd.5762

This Thesis is brought to you for free and open access. It has been accepted for inclusion in Dissertations and Theses by an authorized administrator of PDXScholar. Please contact us if we can make this document more accessible: pdxscholar@pdx.edu. 
AN ABSTRACT OF THE THESIS OF Peter Collier for the Master of Science in Sociology presented July 5, 1989.

Title: Blockmodeling Network Data From Six Small Towns:

An Assessment of Organizational Typologies

APPROVED BY THE MEMBERS OF THE THESIS COMMITTEE:

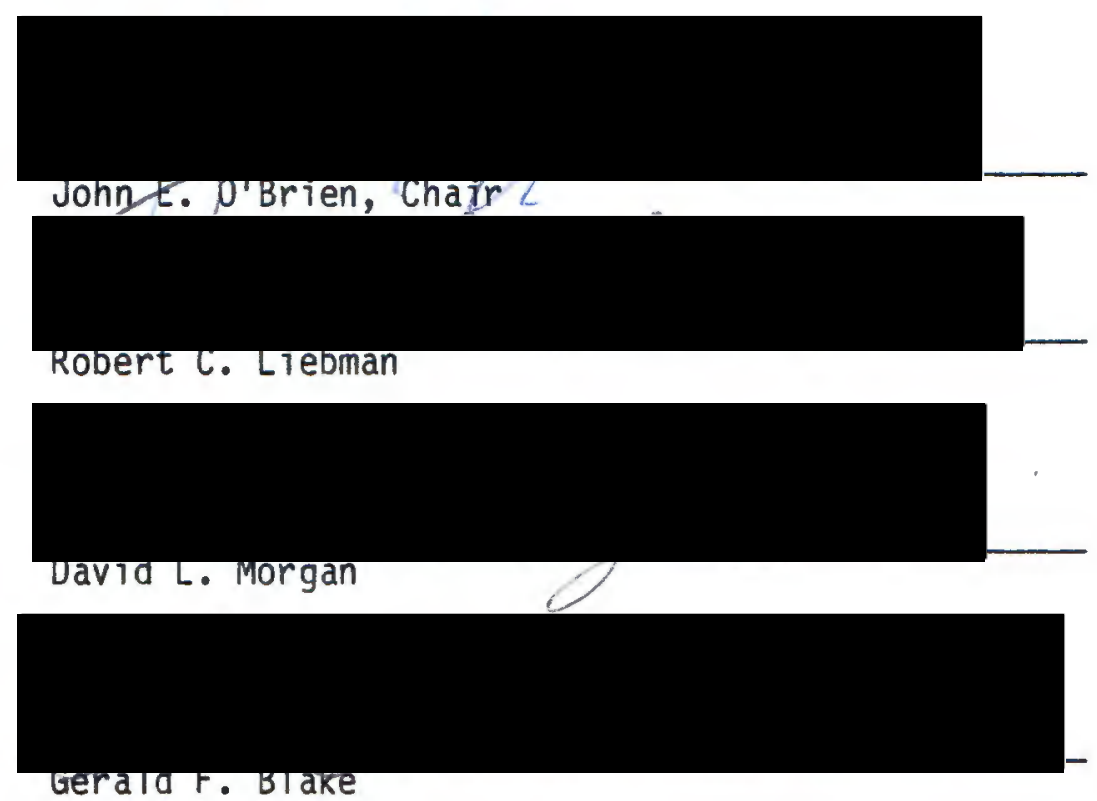

A major question in the study of complex organizations is whether it is possible to develop a useful taxonomy which identifies the crucial aspects of organizations and classifies them in a significant manner. One group of typologies of complex organizations focuses on the relationship between the organization and its environment. The purpose of this thesis is to test the validity of three existing typologies of 
complex organizations, each of which focuses on one aspect of the relationship between organizations and their environment. The major innovation in this research is the use of block modeling, a form of network methodology, to analyze the multiplex relationships and to establish categories of organizations in six towns in Minnesota. This categorical scheme is based on groupings of organizations that share similar patterns of relationships in a community network. The first part of this thesis is an attempt to discover if the three typologies being tested, which were originally developed from data on internal organizational characteristics, are relevant categorical "tools" for distinguishing among "classes" of organizations that were grouped based on the relational data from network analysis of the six Minnesota towns. Three hypotheses are presented, each associated with a different typology to be tested: Hypothesis I - based on inputs (Resource Dependence), Hypothesis II - based on throughputs (Katz and Kahn), and Hypothes is III - based on outputs (Parsonian). Each of these hypotheses predict specific inter-organizational relationships that should be present in the empirical data. A typology is considered relevant for use in this study, if the inter-organizational relationship, predicted by the corresponding hypothesis, is found to be present in the empirical data. All three typologies examined are found to be relevant categorical tools for the network data employed in this study.

Organizations can be thought of as attempting to "position" themselves in their operating environments in such a fashion as to enable themselves to best address their operating problems. However, organizations face not one, but three different problems, relating to: 
1. inputs, 2. throughputs, and 3. outputs. Since in "global terms," any particular organization can occupy only one position in its environment, the question becomes, "Is organizational position most consistent with its input, throughput, or output processes?" Determining the answer to this question is the focus of the second part of this thesis. Block modeling, using the principle of structural equivalence, algebraicly reduces the complete network in each community to "blocks" - sub-groups of organizations that are similar in patterns of interaction across all relationships considered. A four block solution is used in this study. Several measures are employed to compare the data-driven four block partitioning with the theoretically-based four block partitionings derived from each typology of complex organizations. No one typology is shown to best "fit" the data-driven partitioning of the community networks analyzed in this study. Based on the results of the hypotheses tested in the first section of this thesis, and the "tests of fit" conducted in the second section, generalizations concerning the presence of two previously-identified dimensions of community network structure are made. 
BLOCKMODELING NETWORK DATA FROM SIX SMALL TOWNS:

AN ASSESSMENT OF ORGANIZATIONAL TYPOLOGIES

by

PETER J. COLLIER

A thesis submitted in partial fulfillment of the requirements for the degree of

\author{
MASTER OF SCIENCE \\ in \\ SOCIOLOGY
}

Portland State University

1989 
TO THE OFFICE OF GRADUATE STUDIES:

The members of the Committee approve the thesis of Peter Collier presented July 5, 1989

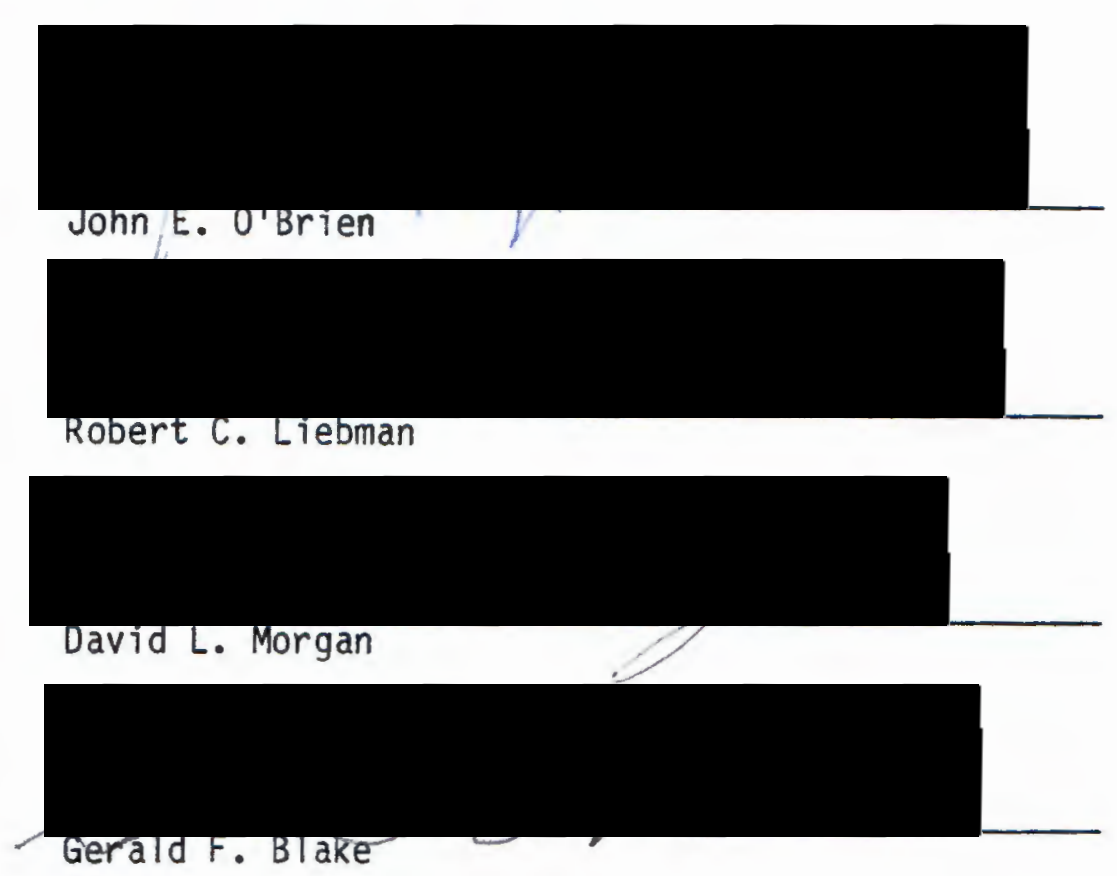

APPROVED:

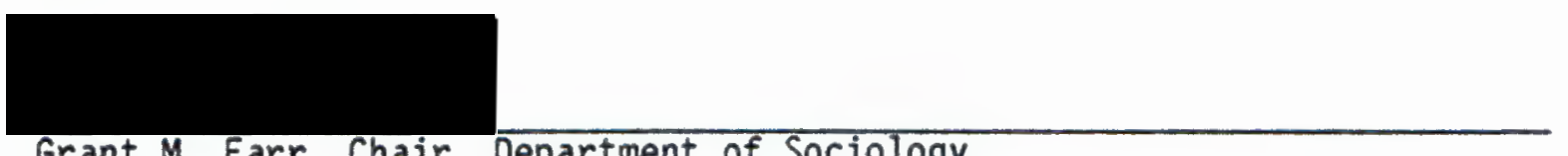

Grant M. Farr, Chair, Department of Sociology

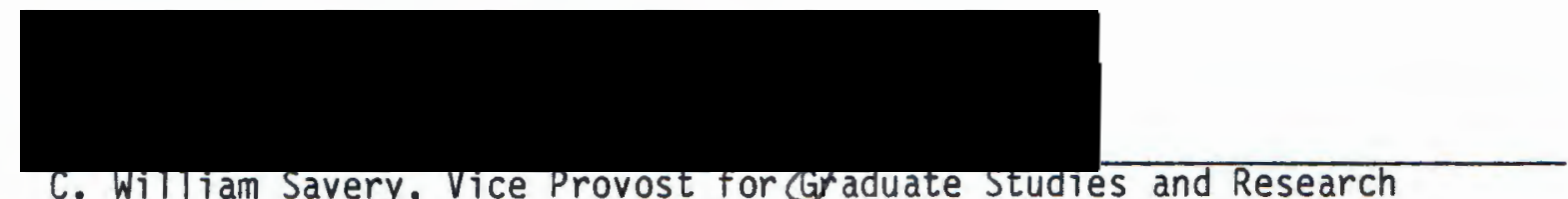


TABLE OF CONTENTS

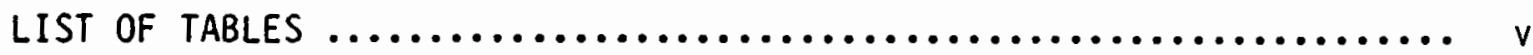

CHAPTER

I INTRODUCTION.

Typologies............................... 4

Open System Approach to Organizations............ 5

Community Network Structure................... 6

Network Analysis.......................... 7

II THEORETICAL LITERATURE ON ORGANIZATIONS............. 11

Open System Approach to Organizations............ 12

Typologies............................... 13

Resource Dependence

Katz and Kahn

Parsonian

III COMMUNITY STRUCTURE.......................... 30

Community Network Structure................ 30

Nodes

Interorganizational Linkages

Modalitites of Network Formation

Hypotheses.

Resource Dependence

Katz and Kahn

Parsonian

IV METHODOLOGY AND FINOINGS: RELEVANCE OF TYPOLOGIES....... 38

The Data Set............................. 38 
Network Analysis........................... 42

Sampling Units

Form of Relations

Content of Relations

Levels of Analys is

Block Modeling.

Fundamental Principles

Algorithm

Patterns in Image Matrices

Tests of Hypotheses.

Resource Dependence

Katz and Kahn

Parsonian

Findings.

$\checkmark$ METHODOLOGY AND FINDINGS: COMPARISON OF TYPOLOGIES.

69

Validity................................... 70

Test of Inclusiveness of Block Membership............ 70

Pair Bonds

Results of Pair Bonds Test

Test of Block Pureness.......................... 79

"b" Statistic

Results of 'b' Statistic Test

Findings.................................... 84

VI CONCLUSIONS....................................... 85

Review of Hypotheses in Context of Community Network...... 86

Summary..................................... 91

Suggestion for Future Research.................... 92

SELECTEd BIBLIOGRAPHY............................... 95 APPENDICES

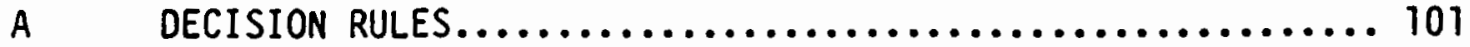

B "b" Statistics values......................... 105 


\section{LIST OF TABLES}

\section{TABLES}

I Types of Organizations Studied...................... 41

II An Across Community Comparison of Image Matrix I and Density Tables............................... 55

III An Across Community Comparison of Image Matrix II and Density Tables.

IV An Across Community Comparison of Image Matrix III and Density Tables.............................. 57

$\checkmark \quad$ An Across Community Comparison of Image Matrix IV and Density Tables.............................. 58

VI An Across Commuinty Comparison of Image Matrix $V$ and Density Tables.

VII An Across Community Comparison of Image Matrix VI and Density Tables.

VIII An Across Community Comparison of Image Matrix VII and Density Tables.

IX Data Driven Partitioning......................... 71

$x \quad$ Parsonian Partitioning............................... 74

XI Katz and Kahn Partitioning........................ 75

XII Resource Dependence Partitioning................... 76

XIII Pair Bonds Measure of Distance Between Data-Driven Partitioning and Three TheoreticallyBased Partitionings........................... 77

XIV Student's t-Test Values......................... 78

XV An Across Community Comparison of "b" Statistic Values..... 82

XVI Decision Rules............................... 102 
XVII. "b" Statistic Values for Image Matrix I in Each Community Studied............................... 106

VIII "b" Statistic Values for Image Matrix II in Each Community Studied............................. 106

XIX "b" Statistic Values For Image Matrix III in Each Community Studied............................. 107

$x x \quad$ "b" Statistic Values for Image Matrix IV in Each Community Studied............................ 107

XXI "b" Statistic Values for Image Matrix V in Each Community Studied............................ 108

XXII "b" Statistic Values for Image Matrix VI in Each Community Studied............................. 108

XXIII "b" Statistic Values for Image Matrix VII in Each Community Studied. 


\section{CHAPTER I}

\section{INTROOUCTION}

The purpose of this thesis is to test the validity of three theoretically-based typologies of complex organizations, each of which focuses on one aspect of the relationship between organizations and their environment. Typologies of complex organizations are developed to facilitate the grouping of these organizations into significant categories. Many traditional typologies are based on distinctions related to variation in the degree of presence of certain internal organizational characteristics. When an organization is considered as part of a community network, a much more relevant criterion for categorization is similarity of patterns of relationships with the other organizations in the network.

The first section of this thesis attempts to determine if the three typologies being tested, originally developed from data on internal organizational characteristics, are relevant categorical "tools" for distinguishing among "classes" of organizations that were grouped based on the relational data from network analysis. As will be shown through the examination of the three different typologies, organizations face not one, but three different problems, relating to: 1. inputs, 2 . throughputs, and 3. outputs. Since in "global" terms, any particular organization can occupy only one position in its environment, the question becomes, "Is organizational position most consistent with its 
input, throughput, or output processes?" Determining the answer to this question is the focus of the second part of this thesis. This paper will attempt to answer the question, "Which of these three theoretically-based typologies of complex organizations is most consistent with the structure of the community networks examined in this study?"

In Chapter II, first the conception of organizations as open systems is discussed. Next, the three theoretical perspectives, and the typologies of complex organizations developed from each perspective that are to be tested in this study, are examined. Each of these perspectives addresses a different aspect of the organization-environment relationship: RESOURCE DEPENDENCE - input, KATZ AND KAHN - throughput, and PARSONS - output.

In Chapter III a brief review of the theoretical literature on community network structure is first presented. Then three hypotheses are proposed. Hypothesis I, relating to inputs, is based on the material from Resource Dependence. Hypothesis II, concerning throughputs, is derived from the work of Katz and Kahn. Hypothesis III, dealing with outputs, is from the material dealing with a Parsonian perspective.

In Chapter IV, issues relating to the data set used in this study are discussed, and a brief overview of network analysis is presented. Next the fundamental principles of block modeling, the primary methodological tool used in this thesis, are described. Then previously identified patterns found in block modeling image matrices are reviewed. The three hypotheses presented in Chapter III are tested to see how well each predicts specific inter-organizational relationships in the empirical data. Finally, findings are presented as to the relevance of 
the three typologies along with some conclusions based upon this information.

The second section examines which typology best describes organizational position in community networks. In Chapter $v$, each theoretically-based partitioning scheme is compared with the data-driven partitioning in terms of: a) the inclusiveness of organizational membership in each block, and b) the "pureness" of relational fit of each partitioning scheme. Several different measures of position are employed in this study. A Pair Bonds score, developed by comparing a partitioning of organizations based on each typology, with a data-driven partitioning based on the network analysis of community networks in six small towns in Minnesota, is used to measure the degree of inclusiveness of organizational block membership in different partitioning schemes. The Carrington, Heil, and Berkowitz "b" statistic is used to compare each theoretically-based partitioning with the data driven partitioning in terms of the "pureness" of the blocks in specific image matrices. The findings of the comparison of typologies are presented.

Finally, in Chapter VI, conclusions regarding the usefulness and "fit" of the three theoretically-based typologies tested in this study will be put forward. Based on the hypotheses tested in the first section of this thesis and the "tests-of-fit" conducted in the second section, generalizations about two previously identified dimensions of community network structure will be discussed. A section of suggestions for future research will conclude this thesis.

In this introduction, an overview of the subject matter relevant to this study will be presented. The following topics will be discussed: a) 
typologies in general, b) the concept of "open systems" as applied to complex organizations, c) the structure of community networks, and d) network analysis.

\section{TYPOLOGIES}

One of the basic purposes of sociology is to identify and describe the primitive attributes of systems of social behavior. A typology - a method of organizing and categorizing "things" (Reynolds, 1971:4) - is one means to this end. To date, more than one typology has been proposed to describe types of organizations. A typology can be thought of as a metaphor representing some fundamental, yet critical, differences between categories of organizations.

Each typology typically addresses a limited number (usually one or two) dimensions. It is acknowledged that these dimensions relate to a small fraction of the many possible organizational characteristics, yet each theorist asserts that they have identified the "key" dimension. For example, Weber emphasizes different "types" of authority; Blau and Scott focus on "Who is the prime beneficiary of organizational actions?"; and Etzioni concentrates on "What is the principle type of incentive used by the organization?" (Blau \& Scott, 1962; Etzioni, 1961; Weber, 1947)

Several theorists within the field of organizational sociology have focused on the external relationships between an organization and its environment. In Chapter II, three theoretical perspectives will be discussed that relate to this approach to complex organizations, as well as the typologies developed from each of these perspectives. The first section of this thesis is concerned with determining if these three 
typologies, originally developed from data relating to internal organizational characteristics, are relevant classificatory tools for categories of organizations in community networks, where groupings are established based on similarities in patterns of inter-organizational relationships.

Because all of the typologies being tested in this thesis deal with some element of the relationship between organizations and their environment, it is helpful to examine what are the underlying concepts and assumptions connected with this perspective.

\section{OPEN SYSTEM APPROACH TO ORGANIZATIONS}

A major difference in perspective among organizational sociologists is how they conceive of the relationship between an organization and its environment. This is basically the difference between a "closed-system" and an "open-system" perspective on complex organizations. (Hall, 1987; Katz \& Kahn, 1966, 1978; Scott, 1987)

Before the advent of an open-system perspective, two approaches dominated approaches to describe social structures such as complex organizations. Either they were: 1. endowed with some vitalistic concept like entelechy, or 2. regarded as closed systems to which the laws of classical physics were applied. In the first case, there was a reliance on some magical purposiveness that accounted for organizational functioning. In the second, environmental forces that affected the. functioning and survival of the "system" were ignored. The laws of Newtonian physics are correct generalizations as they are applied to closed systems. They do not apply in the same way to open systems which 
sustain themselves through the process of continuous interaction with their environment. (Hal1, 1972, 1987; Katz \& Kahn, 1966, 1978; Scott, 1987)

The current emphasis in organizational sociology on the nature of organizational environments (McKelvey, 1982; Pfeffer \& Salancik, 1978), on differences between "types" of organizational environments (DiMaggio \& Powe 11, 1983), and the relationship between the organization and its environment(Aldrich, 1979; McKelvey, 1982; Pfeffer \& Salancik, 1978) make a strong case for the application of the open-system perspective to the study of complex organizations.

In addition to supporting the conceptualization of organizations as open systems, the current emphasis on the organization-environment relationship draws attention to the idea of "communities" of organizations. The environment of a focal organization is made up of other organizations that it engages in relationships with. This is the basis for studies of community network structure.

\section{COMMUNITY NETWORK STRUCTURE}

In "Community Structure as Interorganizational Linkages," Laumann, Galaskiewitz, and Marsden (1978) note that the combination of the study of urban community structure and decision-making, with the literature on formal organizations and administration, has resulted in a new conception of community structure as "an aggregate network of interorganizational relations." (1978:455) Early work in this area by researchers like Hunter (1953) and Laumann (1973) used individual persons as the unit of analysis in the study of community networks. Later efforts suggested 
that organizations, rather than individuals, provide much more stable points of reference for the study of community network structure. (Laumann et al., 1978; Turk, 1970) In this thesis, organizations are used as the units of analysis in this study.

When organizational theorists tried to apply different versions of an "open-system" perspective to the study of complex organizations (Katz \& Kahn, 1966; Parsons, 1960), the critical importance that an organization's environment plays in the organization's activities became evident. Further work by Evan (1966), Warren (1967), and Perrow (1970) pointed out that, for a given organization, those other organizations engaged in transactions with it constitute its environment. Laumann et al. (1978) note as significant a movement away from an emphasis on the analys is of "egocentric" networks and towards the consideration of the total network of interorganizational transactions between all the organizational elements of the network. (Aldrich, 1979; Galaskiewicz, 1979; Turk, 1970) This study focuses on the "complete' or total network in the six communities being examined.

At the time existing typologies of complex organizations were developed, available data were primarily concerned with internal organizational qualities. Since then, newer methodology of social network analys is has provided an additional form of data.

\section{NETWORK ANALYSIS}

The use of network concepts and methods has increased dramatically in studies in economics, political science and education; but it is in sociology and anthropology that this methodology has been applied more 
extensively. (Knoke \& Kuklinski, 1976; Mitchel1, 1969; White et al., 1976)

The conception of social systems as "structured" or organized is found in all established social sciences. In organizational sociology, any of the "traditional" typologies of organizations have this property. For example as noted earlier, Weber structures his "system" of organizations based on differences in forms of authority. (Weber, 1947) But the idea of an "overarching system of relationships among the parts of a social system" is not central to most conventional paradigms in the social sciences. (Berkowitz, 1982:1) The concept of a "system of relationships among the parts of a whole" is central to both the open system conception of organizations and the theoretical work on community network structure. One explanation for why this idea had not previously enjoyed much support in the social sciences may lie in the fact that, until recently, there was not an accepted way of representing, much less measuring, this "type" of structure. This was in direct opposition to the "scientific orientation": definitional precision, operationalism of variables (specification of observed phenomena), and consistency in measurement. Without an effective, practical method of measuring patterns of activity in social systems, the notion of this "over-arching," relational-based structure was disregarded on the basis of being, at the same time, too vague and too complex to use in analysis of these systems.

This all changed with the introduction of a "tool" developed in mathematical graph theory, the NETWORK. Social scientists seized upon the idea of a network as a means of describing relationships between and among, individuals, family groups, organizations, and many other categories of elements identified in complex social systems. 
Network analysis incorporates two assumptions about social behavior that are significantly different from more traditional approaches. First, any actor(in this case: organization) typically participates in a social system that involves many other actors. These actors are important references points in each other's decisions. An individual actor's perceptions, beliefs, and actions may be affected and influenced by the number and nature of the relationships that actor has with other members of the social system. (Knoke Kuklinski, 1982:9)

Second, it is important to identify and distinguish the various levels in a social system, where "social structure is regularities in the patterns of relations among concrete entities." (White, et al., 1976:733). Because of its emphasis on the relations that connect social positions within a system, network analysis can detect emergent social phenomena that have no existence at the level of the individual actor. Relational measures identify emergent properties of a social system that are impossible to measure by the aggregation of individual member's attributes. Emergent properties have been shown to significantly affect both the behavior of individual network members as well as general system performance. (Knoke \& Kuklinski, 1982:9-11)

Relationships may be considered the building blocks of network analysis. The shift from attribute-based to relation-based representations of social structure was innovative and distinctive in regards to previous efforts in the social sciences.

Instead of trying to describe the structure of an organization by "getting inside of its head," social network analysis derives internal structure by looking at behaviors and relationships--"what does an 
organization do?" In effect, this amounts to using "outside" data to ascertain "inside" reality. This property makes network analysis an appropriate methodology for addressing the central questions in the first section of this research, "Are these three typologies of complex organizations, originally developed based on internal organizational characteristics, relevant categorical tools for grouping organizations in community networks?" All three theoretically-based typologies are shown to be relevant categorizational tools for the community networks examined in this study. In the second section of this thesis different methodological tests are employed to show whether organizational position is most consistent with its input, throughput, or output processes. 


\section{CHAPTER II}

\section{THEORETICAL LITERATURE ON ORGANIZATIONS}

The first part of this thesis attempts to determine if the three typologies being tested are relevant categorical tools for the community network data to be examined in this study. The three theoretically-based typologies of complex organizations to be tested each focus on a different aspect of the relationship between an organization and its environment. Therefore a discussion of the open system approach to organizations will begin this chapter. Next, each of the three theoretical perspectives on complex organizations, and the typologies that are based upon each of these perspectives, will be examined. The three perspectives that are the bas is for the typologies are: 1. a resource dependence model, based on the work of Jeffery Pfeffer, Gerald Salancik, and Howard Aldrich; 2. an "open-system" model, as put forth by Daniel Katz and Robert Kahn; and 3. a Parsonian model, developed by Talcott Parsons.

Although any set of concepts can be used to organize and categorize phenomena, developing a typology is not easy. Doing so typically depends on both theoretical and empirical criteria. This means that to be effective, a useful typology should display both "construct" validity (having been theoretically derived), and empirical validity (fitting the available data). This thesis is principally concerned with examining the 
second of these types of validity, relative to existing organizational typologies.

Because all of the typologies being tested in this thesis deal with some element of the relationship between organizations and their environment, it is helpful to examine what are the underlying concepts and assumptions connected with this perspective.

\section{OPEN SYSTEM APPROACH TO ORGANIZATIONS}

An organization is an open system to the degree that it takes the external environment into account; it is closed to the degree that it does not. (Ha11, 1987; Maurer, 1971; Scott, 1987) An open system approach to organizations is one in which:

1. The organization is conceptualized as an IMPORTING TRANSFORMING-EXPORTING system. Importing is the same as "inputs," transforming is the same as "throughputs," and exporting is the same as "outputs."

2. The organization is viewed as transacting with environmental elements with respect to the importing and exporting of people, material, energy, or information.

3. The processes of importation and exportation are characterized by some degree of uncertainty.

4. Reception of exports by elements in the external environment provides the organization with additional imports for transformation.

5. The organization is viewed as a subsystem of a supersystem, and

6. Some phenomena, internal to the organization, are viewed as partially determined by phenomena external to the organization. (Hall, 1987; Mauer, 1971; McKelvey, 1982; Scott, 1987) 
Organizations export not only products or services, but also information about their internal operations (McKelvey, 1982; Perrow, 1986; Weick, 1976), their behavior on their boundaries (Scott, 1987), and functional as well as dysfunctional byproducts. (Katz \& Kahn, 1966, 1978) An open system perspective does not conceptualize an organization as simply reacting to elements in its external environment. The model used is interactional. An organization shapes as well as is shaped by its environment The environment presents the organization with opportunities for exploitation and controllable external factors, as well as confronts it with uncontrollable constraints and contingencies. (Hall, 1987; Maurer, 1971; Pfeffer, 1978; Pfeffer \& Salancik, 1978; Scott, 1987)

\section{TYPOLOGIES}

Several typologies of complex organization utilize part or all of an open system perspective in the way they conceptualize the operations of an organization and how it interacts with its environment. Three of these typologies - RESOURCE DEPENDENCE, KATZ AND KAHN, and PARSONIAN will now be examined in more depth.

\section{Resource Dependence}

A resource dependence model is strongly rooted in an open system framework. A primary focus of this perspective is on organizational inputs. The point is made that it is not possible to understand the structure or behavior of a organization without understanding the context within which it operates. (Aldrich \& Pfeffer, 1976; Hall, 1987; Pfeffer, 1978, 1982; Pfeffer \& Salancik, 1978; Scott, 1987) This perspective 
views the environment as a critical influence on the organization, but in this model organizational decisions and actions are also important. (Aldrich \& Pfeffer, 1976; Pfeffer, 1978, 1982; Pfeffer \& Salancik, 1978; Scott, 1987)

An organization's survival depends on organizational effectiveness. Organizational effectiveness is based upon the management and control of demands upon the organization, particularly the demands of interest groups upon which the organization depends for resources and support. The key to organizational survival is the ability to acquire and maintain resources. (Ha11, 1987; Perrow, 1986; Pfeffer \& Salancik, 1978; Pfeffer, 1982; Scott, 1987)

This perspective is based upon four basic assumptions:

1. No organization can generate all the various necessary resources critical to its operation. It is also impossible for any organization to perform all the activities(behaviors) necessary for the organization to be self-sufficient. (Hall, 1987; Pfeffer, 1978, 1982; Pfeffer \& Salancik, 1978; Scott, 1987)

2. The conditions referred to in assumption \#1 means that organizations must depend on the environment for resources. Resources can be in the form of finances, raw materials, personnel, services, productions operations the given organization does not/or does not wish to perform, or technological innovations. (Hall, 1987; Pfeffer, 1978, 1982; Pfeffer \& Salancik, 1978; Scott, 1987)

3. Decisions are made within organizations. Also these decisions are made within, and in terms of the political context of the organization. These decisions focus on problems associated with environmental conditions that face the organization. (Hall, 1987) 
4. Organizations are not passive, waiting for the environment to "decide their fate." Organizations attempt to deal actively with the environment; they attempt to manipulate the environment to their own advantage by making strategic decisions on how they will adapt to changes in the environment. (Pfeffer, 1978, 1982; Pfeffer \& Salancik, 1978; Scott; 1987)

The sources of resources in the environment are other organizations. Organizations that interact in the process of acquiring resources build patterns of interdependence. (Ha11, 1987; Perrow, 1986; Pfeffer \& Salancik, 1978; Pfeffer, 1982; Scott, 1987) This leads Hall $(1987: 303)$ to suggest that a better name for this model might be an "interorganizational resource dependence model."

Just because organizations are dependent on their environments for survival and success does not necessarily make their existence problematic. There is no problem if stable supplies of the resources necessary for organizational survival are available, even if these resources are outside of the control of the organization in question. Problems that arise are not as much a result of organizational dependence upon an environment, as much as because the environment is not dependable. (Pfeffer \& Salancik, 1978; Pfeffer, 1982)

Environments change; they are not static. New organizations develop, old organizations disappear. The supply of specific resources becomes more plentiful or harder to acquire. When environments change, organizations are faced with the choice of problematic survival chances, or of changing their activities to deal with these environmental factors. (Pfeffer \& Salancik, 1978; Pfeffer, 1982; Scott, 1987) 
It is not necessarily true that every event that confronts an organization affects it. In some cases, organizations are "buffered" from environmental effects. An example of this would be the situation where an organization with a large inventory of necessary resources would not have its operation critically affected by a short-term scarcity of those resources. Also, for a given organization, not all environmental occurrences are equally significant; some are not important enough to require a response. (Pfeffer \& Salancik, 1978; Pfeffer, 1982; Scott, 1987)

This type of relationship between an organization and the other organizations in its environment has been called "loose coupling" (Perrow, 1986; Scott, 1987; Weick, 1976) Loose coupling works as a safety device for ensuring a higher rate of organizational survival.

"If organizational actions were completely determined by every changing event, organizations would constantly confront potential disaster and need to monitor every change while continually modifying themselves. The fact that environmental impacts are felt only imperfectly provides the organization with some discretion, as well as the capacity to act across time horizons longer than the time it takes for an environment to change." (Pfeffer \& Salancik, 1978:13)

Constraints on organizational behavior result from situations of asymmetric interdependence. One or more elements of an organization's environment have the power and discretion to control needed resources and enforce demands upon the organization in question. The greater the dependence on the external organization, the greater its influence on the focal organization. (Hall, 1987; Pfeffer, 1978, 1982; Pfeffer \& Salancik, 1978; Scott, 1987) 
This model emphasizes that organizational actions are determined by an "enacted" environment--the organization responds to that it receives, perceives, and believes about the world. (Pfeffer \& Salancik, 1978; Pfeffer, 1982) Which "bits" of information from the environment are received and prioritized largely determine the "nature" of the enacted environment.

The concept of "strategic choice" is an important part of the resource dependence model. (Hall, 1987; Scott, 1987) This refers to the fact that a decision is made among a set of alternative strategies that the organization will utilize in its dealings with the environment. It is important to note that there is not just one optimal structure or preferred course of action. (Pfeffer, 1978, 1982; Pfeffer \& Salancik, 1978) Internal power arrangements within the organization play a crucial role in determining which choices are made and implemented. (Hall, 1987)

There are limitations on the range of choices available to organizational decision makers. Laws and other legal barriers may preclude the movement of an organization into a particular area. Economic factors also play a major role. There are some projects that are too expensive for an organization to undertake. Some alternatives may only be viable for organizations of a specific size. (Hall, 1987; Pfeffer, 1982) Finally, from a phenomenological standpoint, organizational decision makers act upon the environment in terms organizationally-specific perceptions, interpretations, and evaluations. Different organizations may perceive the same occurrence as significant or unimportant depending on the symbolic system of the organization in question. (Hall, 1987; Sanders, 1982; Scott, 1987) 
Different organizations require different resources to survive. There are also some resources that all organizations require, but the "weight" attached to these values originates from the value system of the organization. Among the "key" resources that have been identified are: money, personnel, technology, raw materials, access to influentials, symbolic support, and information. (Clark, 1968)

Organizations can be categorized on the basis of which of these resource "types" are most critical to the survival of the organization in question. The four types of key resources that are used as the basis for the typology employed in this study are:

1. Raw Materials: These are elements that are transformed in the manufacturing process. Examples of this type of resource would include steel, timber, and coal. This category would also include wholesale finished goods that are then sold by retail businesses, as well as food-stuffs.

2. Money: This element is the capital resources required for operations by all organizations. Information is also included in this category due to the increasing value placed upon information in modern societies. Peter Drucker (1982) has noted that information outputs have become as important as capital outputs in the services provided by financial institutions in the United States.

3. Personnel/Clients: People are a key resource to many organizations. This category includes employees to accomplish the goal.s of the organization, as well as clients for the services provided by specific organizations. Social service agencies cannot exist without the clients they provide services for. 
4. Access to Influentials: A key resource for many organizations is to be in a position top be able to give input to influential decision makers. Access to these key individuals facilitates the realization of specific organization goals.

The primary focus of the resource dependence model is on how organizations choose to deal with environmental contingencies. By emphasizing inputs, how organizations acquire the resources critical to their survival, this perspective is very relevant to the study in question. Resource dependence identifies an organizational-environmental linkage that is not present in closed-system conceptions of organizations. The identification of loosely coupled interorganizational systems is another shared concept between this model and an open system perspective.

\section{$\underline{\text { Katz and Kahn }}$}

Daniel Katz and Robert Kahn, two social psychologists, developed a typology of complex organizations that was heavily influenced by the work of Parsons and general systems theory. (McKelvey, 1982) Katz and Kahn are particularly concerned with the work, or THROUGH-PUT, that gets done by an organization; specifically as this relates to the organization's contribution to the larger social structure. (Katz \& Kahn, 1966, 1978; Kuhn \& Beam, 1982; McKelvey, 1982; Ramos, 1981)

These authors categorize complex organizations in terms of their GENOTYPIC FUNCTION. This refers to the type of activity an organization performs in its role as a subsystem of the larger society. Katz and Kahn categorize organizations into 4 broad classes: 
1. PROOUCTIVE/ECONOMIC ORGANIZATIONS: These organizations are concerned with the creation of wealth, the manufacture of goods, and providing services to segments of or the entire general public. These are subdivided into: a. farming and mining; b. manufacturing and processing; and c. service and communication. The outputs of these organizations provide for most of the basic human needs (examples: food, shelter, clothing). These outputs also function as inducements to keep individuals productive and contributing to the ongoing society. (Baird \& Hammer, 1979; Katz \& Kahn, 1966, 1978; Kuhn \& Beam, 1982; McKelvey, 1982)

2. MAINTENANCE ORGANIZATIONS: These organizations are concerned with the socialization of individuals in the society. Examples would be churches and schools. These are subdivided into: a. direct functions education, indoctrination, and training, and b. restorative functions health, welfare, and institutions of reform and rehabilitation. These organizations provide the normative integration of a society. (Hall, 1972, 1987; Katz \& Kahn, 1966, 1978; McKelvey, 1982)

3. ADAPTIVE ORGANIZATIONS: These organizations are concerned with the creation of knowledge, and the application of information to existing problems. Research organizations, and other collective groups and associations oriented to problem-solving make up this category. These organizations provide part of the informational integration of the society. (Hall, 1972, 1987; Katz \& Kahn, 1966, 1978; McKelvey, 1982)

4. MANAGERIAL/POLITICAL ORGANIZATIONS: These organizations are concerned with the "...adjudication, coordination, and control of resources, people, and subsystems." (Katz \& Kahn, 1966:112) The prime player here is the state or government, in its role as the major 
authority structure of the society. Other, less influential elements such as labor unions and special interest groups are also part of this category. (Hall, 1972, 1987; Katz \& Kahn, 1966, 1978; McKelvey, 1982)

Katz and Kahn build upon Parsons' work, but with a slight social-psychological "bent." for them, for any society to endure it must:

1. Provide economic activities and opportunities which will serve to meet the basic needs and provide the basic services required by the members of the society;

2. Develop and maintain a central set of values and norms with socializing agencies to instill and implant these belief systems; and also to provide the necessary training required by societal members to meet their social roles;

3. Insure integration and compromise between interest groups by establishing an authoritative decision-making structure to allocate resources within the society; and

4. Foster the development of specialized organizations for the advancement of knowledge and the application of existing knowledge to the solution of problems that are important to the whole society. (Katz \& Kahn, 1966:113)

These tasks are distributed among organizations within a society. A specific organization typically specializes in one particular function, but also contributes, at a lesser level, to other functional areas. (Katz \& Kahn, 1966, 1978; Kuhn \& Beam, 1982; Ramos, 1981)

After identifying the four genotypic (first order) classes, Katz and Kahn then select four second order characteristics important for 
structures. The energy transformations may involve either the processing of objects or the molding of people. For example, an educational institution or hospital is concerned with changing people who come within its boundaries and who become temporary members of the organization. Human beings as objects of a change process require different organizational processes than materials transformed in a manufacturing plant. (Ha11, 1987; Katz \& Kahn, 1966, 1978). Human beings are reactive, participating objects in any molding process, and their cooperation to enter many organizations must first be insured. (Goffman, 1961)

Two basic difference must be recognized in dealing with systems processing people as against physical objects. First, the internal procedures and forms must attract and motivate temporary members who are to be trained or treated. There must also be a considerable area of discretionary power within the staff roles in the organization charged with the responsibility for training and treatment. The reactive nature of subjects or patients requires reciprocal spontaneity on the part of the staff. (Hall, 1987; Katz \& Kahn, 1966, 1978)

Second, the external transactions of "people-processing" organizations are not those of the marketplace in any immediate or direct sense. These institutions are less open to the immediate influence of the marketplace and more concerned with long-range outcomes. Support comes indirectly, through taxes, subsidies, or gifts. Also, outputs are consumed indirectly, through hiring practices or the return of well patients to the community. (Hall, 1972; Katz \&ahn, 1966, 1978; McKelvey, 1982; Parsons, 1960) 
structures. The energy transformations may involve either the processing of objects or the molding of people. For example, an educational institution or hospital is concerned with changing people who come within its boundaries and who become temporary members of the organization. Human beings as objects of a change process require different organizational processes than materials transformed in a manufacturing plant. (Hall, 1987; Katz \& Kahn, 1966, 1978). Human beings are reactive, participating objects in any molding process, and their cooperation to enter many organizations must first be insured. (Goffman, 1961)

Two basic difference must be recognized in dealing with systems processing people as against physical objects. First, the internal procedures and forms must attract and motivate temporary members who are to be trained or treated. There must also be a considerable area of discretionary power within the staff roles in the organization charged with the responsibility for training and treatment. The reactive nature of subjects or patients requires reciprocal spontaneity on the part of the staff. (Hall, 1987; Katz \& Kahn, 1966, 1978)

Second, the external transactions of "people-processing" organizations are not those of the marketplace in any immediate or direct sense. These institutions are less open to the immediate influence of the marketplace and more concerned with long-range outcomes. Support comes indirectly, through taxes, subsidies, or gifts. Also, outputs are consumed indirectly, through hiring practices or the return of well patients to the community. (Hal1, 1972; Katz \& Kahn, 1966, 1978; Mckelvey, 1982; Parsons, 1960) 
It should be noted that this distinction is rapidly disappearing as more and more social service agencies import techniques and philosophical components from the larger business community. A good example is the increase in "for-profit" hospitals in the health-care field, an area that was traditionally dominated by non-profit and government supported facilities. These organizations are characterized by external marketplace transactions.

The contrast between organizations whose throughput activity directly involves people and those whose throughput activity involves objects is not absolute, because organizations concerned primarily with the manufacture of physical products must nevertheless deal appropriately with the human tools for getting the job done. Machine theory is highly appropriate for the processing of material objects through the use of tools. Its weakness is in applying the same logic to human instruments in factory production is often compensated for by its efficiencies in dealing with the processing of materials (objects). Where the materials being processed are human beings, this compensatory factor is lacking. (Hal1, 1972, 1987; Katz \& Kahn, 1966, 1978; McKelvey, 1982)

The categorical distinction between people-processing and object-processing organizations is not exhaustive. A further difference has been noted between organizations that process people and those that seek to change them. (Hall, 1987)

Katz and Kahn discuss the interplay between the organizational dimensions they identify (second order factors) and the categorization scheme they developed based upon societal function performed (first order factors). The emphas is these authors place on throughput, or the nature 
of the work being done by an organization, is particularly relevant to this study. (Katz \& Kahn, 1966:128-147)

Parsonian

A Parsonian model is primarily concerned with organizational outputs. Parsons' theory of organizations is based upon his theory of social systems. All social systems must solve four basic problems:

1. ADAPTATION: The accommodation of the system to the demands of the environment, and the active transformation of the external situation;

2. GOAL ATTAINMENT: The defining of objectives, and the mobilization of resources to obtain them;

3. INTEGRATION: Establishment and organization of a set of relations, among the member units of a system, that serve to coordinate and unify them into a single entity; and

4. LATENCY: Maintenance over time of the system's motivational and cultural patterns. (Hall, 1987; McKelvey, 1982; Parsons, 1960; Scott, 1987)

For Parsons, the existence of organizations is a result of the differentiation of labor in society. When the same structural unit produces all the necessary outputs for survival and also utilizes these same outputs, there is no need for the development of a system involving the differentiation of specialized organizations. A good example would be a primitive society. The structural units of this society, generally kinship units, are "self-sufficient." They produce all of the necessary outputs for their survival. A primitive society does not generally have what we would call clear-cut differentiated organizations. (Parsons, 1960:18; Scott, 1987) 
Organizations are concerned with goal-oriented endeavors. Parsons calls attention to the relative importance placed on goal-attainment in organizations. Organizations are social systems placing higher priority on those processes by which goals are set and resources are mobilized for goal attainment than is the case in other social systems. The nature of the goal may vary from organization to organization, but the "purpose" of an organization is to realize that goal. (Parsons, 1960; Scott, 1987)

The goal of an organization, when viewed from the larger perspective of the system that the specific organization is a sub-unit of, is the specialized function that organization performs for the larger system. This relationship is the primary link between the organization and the larger system. This linkage also provides the basis for Parsons' classification of types of organizations. (Hall, 1987; McKelvey, 1982; Parsons, 1960; Ramos, 1981; Scott, 1987)

Organizations are classified in terms of the "types of goals" or "function" the realization of which is their central purpose. Viewed from the "inside," from the perspective of the specific organization, the purpose of the organization is its "goal." Viewed from the "outside," from the perspective of the larger system, the same purpose is the organization's "function." (Hall, 1987; McKelvey, 1982; Parsons, 1960; Perrow, 1986; Ramos, 1981; Scott, 1987)

The principle types of organizations identified by Parsons are:

1. ADAPTATION: Organizations oriented to economic production. An example would be a business firm. Parsons makes the point that production is used here in the sense of "adding value." He does not intend to limit this category to only physical production or 
manufacturing organizations. (Hall, 1987; Parsons, 1960; Perrow, 1986; Scott, 1987)

2. GOAL ATTAINMENT: Organizations oriented to political goals, and to the generation and allocation of power in society. Included in this category are most government agencies. Purchasing power is controlled by the allocation of credit. For this reason, Parsons includes banks in this group. He also notes that incorporation can be viewed as allocation of power in a political sense. This is the reason for including the corporate aspects of formal organizations in this category. (Hall, 1987; Parsons, 1960; Perrow, 1986; Scott, 1987)

3. INTEGRATION: Integrative organizations, on a societal level, contribute to efficiency rather than effectiveness. They are concerned with mediating conflicts, and motivating the members of society to fulfill institutionalized expectations. Examples of organizations of this type are courts and the legal profession, political parties, interest groups, and social-control agencies, like hospitals. (Hall, 1987; Parsons, 1960; Perrow, 1986; Scott, 1987)

4. LATENCY: Pattern-maintenance organizations, especially those that focus on "cultural," "educational," and "expressive" functions. Examples of this group would include organizations such as museums, schools, and churches. (Hall, 1987; McKelvey, 1982; Parsons, 1960; Perrow, 1986; Scott, 1987) Parsons also includes the family in this category, because he says that "in a society so highly differentiated as our own, the nuclear family approaches more closely the characteristics of an organization than in other societies." (Parsons, 1960:46) 
In his work, Parsons attempts to develop and perfect a limited set of abstract concepts that could then be adapted for use in examining the structure and functioning of diverse social groupings. Parsons' framework is quite comprehensive, encompassing the formal and rational aspects of organizations as well as the informal. He is more explicit than other theorists in defining the system needs that must be served for survival. (Hall, 1987; McKelvey, 1982; Scott, 1987)

In his theory of organizations, Parsons attempts to first define an organization by locating it within the structure of the society relative to other categories of social structure. He emphasizes that an organization is a social system which is organized and oriented to the attainment of a particular kind of goal. He reiterates his concept of sub-systems within systems from his earlier work of social systems by pointing out that the attainment of a specific goal on an organizational level, is the fulfillment of a functional requirement on the system or societal level.

Parsons uses the same basic classification of functional problems of social systems as the basis for his classification of types of organizations. A central assumption of this perspective is to conceive of the organization, or social system, as a "natural whole." In this model organizations strive to maintain homeostasis. Of particular importance are the mechanisms by which equilibrium is maintained. The goal orientation of the organization reflects its strategy for maintaining its own equilibrium. As sub-systems of a larger system (i.e., society - organizations themselves are the homeostasis maintaining mechanisms of the larger system). (McKelvey, 1982; Scott, 1987) 
Parsons' work emphasizes the importance of the organizationalenvironmental relationship. The environment is viewed more as a stabilizing element that legitimizes and sustains the organization in the pursuit of specific organizational goals, rather than as a source of resistance and uncertainty. (Scott, 1987) As McKelvey (1982:54-55) notes, from a Parsonian perspective, one could view the environment--in this case the larger social system--as exerting forces on organizations that lead them to specialize in one of Parsons' four functional groups. In the preceding section of this thesis three organizational perspectives as well as specific typologies associated with each perspective have been examined. Each of these theoretically-based typologies focuses on a different aspect of the relationship between an organization and its environment: 1. Resource Dependence - inputs, 2. Katz and Kahn - throughputs, and 3. Parsonian - outputs. Each of these theoretically-based typologies yields a structure which partitions the universe of organizations into four categories: Resource Dependence Raw Materials, Money/Information, Personnel, and Access to Influentials; Katz and Kahn - Productive, Maintenance, Adaptive, and Managerial/ Political; and Parsonian - Adaptation, Goal Attainment, Integration, and Latency. Through the use of block modeling methodology, a four category model of community network structure will be developed, based on empirical data on inter-organizational networks in six small towns in Minnesota. In Chapter $V$ of this thesis, the validity of each of the theoretically-based typologies will be assessed on the basis of how well each "fits" the four block model of community network structure developed by the analysis of the empirical data from the six small towns in Minnesota. 


\section{CHAPTER III}

\section{COMMUNITY STRUCTURE}

Do the three typologies discussed in Chapter I distinguish among categories of organizations that were grouped based on similarities of patterns of interaction in community networks? In this chapter, first a review of the literature on community network structure will be presented. Then two postulates and three hypotheses will be proposed. The hypotheses will be tested in Chapter III to determine their relevance for use in this study.

\section{COMMUNITY NETWORK STRUCTURE}

The first set of studies on inter-organizational relationships and structure took place in the area of community network analysis. Major breakthroughs began to emerge as work done by these researchers started to overlap with the work being done by organizational theorists. In "Community Structure as Interorganizational Linkages", Laumann, Galaskiewitz, and Marsden (1978) note that the combination of the study of urban community structure and decision-making, with the literature on formal organizations and administration, resulted in a new conception of community structure as "an aggregate network of interorganizational relations." (1978:455) Early work in this area by researchers like Hunter (1953) and Laumann (1973) used individual persons as the unit of analys is in the study of community networks. Later efforts suggested 
that organizations, rather than individuals, provide much more stable points of reference for the study of community network structure. (Laumann et al., 1978; Turk, 1970) As noted earlier, this thes is uses organizations as the units of analysis in this study.

When organizational theorists tried to apply different versions of an "open-system" perspective to the study of complex organizations (Katz \& Kahn, 1966; Parsons, 1960), the critical importance that an organization's environment plays in the organization's activities became evident. When studying community networks, it is necessary to slightly modify the original definition of social networks that developed from anthropological research. (Barnes, 1969; Mitchell, 1969) Laumann et al. (1978:458) describe a social network as "a set of nodes (organizations) linked by a set of relationships (transfer of funds, shared personnel) of a specified type." What will follow now is a discussion of the literature on community structure in terms of the three basic elements of interorganizational network structure: nodes, linkages, and modalities of network formation.

\section{Nodes}

The first step in the analysis of a network is to determine what are the elements that make up the "system" in question. Exchange theorists (Benson, 1975; Levine \& White, 1961) put forth the view that the network "set" should include all organizational units that are potential partners in exchange transactions. This is because these organizations control resources essential to other organizations in the "system." However it should be noted that it is possible for an organization to enter in an exchange relation with another organization which is not located in the 
same "local" area as the focal organization. When the interorganizational network to be analyzed is a "community," geographical proximity becomes a second standard by which network boundaries are established. (Laumann et al., 1978)

\section{Interorganizational Linkages}

Laumann and Pappi (1976) stress the importance of what they call the axiom of relation-specific structures. This states that interorganizational linkages of one type (e.g., transfer of funds, shared personnel) do not necessarily imply bonds of any other type between the same organizations. This is consistent with the research done by Hunter (1953:62) on community power structure in "Regional City": "... I doubt seriously that power forms a single pyramid with any nicety in a community the size of Regional City. There are pyramids of power in this community which seem more important to this discussion than a single pyramid."

Galaskiewicz (1979) also identifies the presence of a variety of what he calls "interorganizational resource networks" in a given community. These resource networks could be thought of as "dimensions," corresponding to a linkage or set of linkages all concerned with a particular category of network relation. (Example: "Money" dimension: made up of two types of relations or linkages: "receive funds from," "send funds to"). The position an organization occupies in each of these networks reflects "what it does," since an organization's position in a network determines how much control it has over that particular resource. (1979:64-65) For example, manufacturers, retailers and financial institutions all perform important economic functions in a 
community. According to Galaskiewicz, they will have a greater need to control the distribution of funds in the interorganizational network, and will be more central in the money dimension.

These findings are consistent with research done by Beth Mintz and Michael Schwartz in The Power Structure of American Business (1985). These authors put forth the "Theory of Financial Hegemony" which attempts to explain intercorporate power in terms of the dominance of financial institutions in the corporate interlock network. Financial hegemony is a form of structural hegemony. Structural hegemony operates when the actions of one social institution (or coordinated group of institutions) determine the viable options available to other institutions and individuals. (1985:xii)

In this study several different "types" of interorganizational linkages, mapped on the same set of nodes, are examined in six different communities.

\section{Modalities of Network Formation}

So far this review has focused on a "sub-system" level--the nodes and linkages that are the components of a community network. The examination of the modalities of network formation shifts the focus to a "system" level. This is where the aspects of the overall social context that, in various ways, influence the pattern of the community network are considered. Laumann et al. $(1978: 466)$ identify two primary modalities of network formation: the competitive mode, and the cooperative mode.

In the competitive mode of network formation, norms characteristics of business firms in a perfectly competitive market are the distinguishing feature. (Parsons \& Smelser, 1956) Linkages between 
organizations are strictly instrumental. The emphasis is on obtaining necessary inputs and disposing of products.

In a cooperative mode of network formation, it is assumed that the welfare of the community, as a whole, will be maximal when organizations with different goals, consciously cooperate to attain a collective purpose which benefits the community. (Laumann et al., 1978) CONTINGENT COOPERATION, where organizations balance their commitments to welfare of the "community" with their own more specialized goals, has been identified as the most common form of this modality. (Laumann et al., 1978; Levine \& White, 1961)

Clark (1968) identifies the voluntary nature of an organization's commitment to the "good of the community" as the major weakness of the mode of contingent cooperation. This led to the emergence of a second cooperative mode of network formation, MANDATEO COOPERATION. (Laumann et al., 1978) In this mode there usually is a centralized control agency, often with the ability to control funding, which also has the power to structure or restructure the entire network. This typically involves government organizations, but it should be noted that private organizations, subject to control by government through regulation or funding restrictions, can also be involved. (Laumann et al., 1978:468) For example, it has been noted (Rothman, 1974; Schottland, 1963) that government programs directly affect the planning of public and voluntary organizations at both local and state levels. Both competitive and cooperative modes of network formation are evident in the interorganizational community networks examined in my study. 
HYPOTHESES

In order to test the hypotheses presented in this thesis, it is necessary to make certain assumptions about inter-organizational field forces. Two POSTULATES are proposed as a foundation for the hypotheses to be tested.

POSTULATE I: For any organization that is part of an organizational network, structural position within the network will be determined by the function the organization is performing in regard to maintaining the network.

It is not important what criterion is used. The key point is that the function the organization performs in maintaining the stability of the "system" determines the position that organization occupies in the network.

POSTULATE II: For any set of organizational networks, organizations that fulfill a similar function will occupy similar structural positions.

This is the basis for the concept of structural equivalence. Organizations with similar patterns of relationships can be said to fulfill similar functions, and occupy similar network positions.

Each of the theoretically-based typologies examined in this study predicts inter-organizational relationships which should be visible in the empirical data from the community networks in the six towns in Minnesota. These relationships are presented in the form of three hypotheses, one derived from each theoretically-based typology. In Chapter IV, blockmodeling methodology is introduced which will facilitate the testing for the presence of the predicted inter-organizational relationships in specific community networks. A typology will be 
considered relevant for use in this study, if the inter-organizational relationship, predicted by the corresponding hypothesis, is found to be present in the empirical data.

\section{Resource Dependence}

HYPOTHESIS I: The greater the dependence on external-tothe-organization sources of funding by the members of an organizational network, the more dominant the positions of financial-resources controlling organizations. (Inputs)

Organizations will respond to an interest group to the extent that it has direct control over resources needed by the organizations.

\section{Katz and Kahn}

HYPOTHESIS II: The greater the similarity between organizational throughputs, the greater the probability of inter-organizational cooperation. (Throughput)

Organizations that process the same throughput will be more likely to engage in cooperative projects involving the pooling of personnel to address problems of concern to both organizations.

\section{Parsonian}

HYPOTHESIS III: The greater the importance of an organization's output towards meeting a functional requirement of the organizational network, the more dominant the organization's position will be in the network. (Outputs)

The element of an inter-organizational network that addresses a specific functional requirement of that network, should occupy a dominant 
position in any relationships directly pertaining to addressing that particular need.

In this chapter, the literature on community network structure has been reviewed, and a "tie" has been shown to exist between organizational theorists who focus on the organization-environment relationship, and community network theorists with their conception of community structure as "an aggregate network of interorganizational relations." (Laumann et al., 1978:455) What is needed is some sort of "bridge" to link the two groups. This bridge is supplied by a new kind of network methodology-block modeling--which is introduced in Chapter IV. 
CHAPTER IV

METHODOLOGY AND FINDINGS: RELEVANCE OF TYPOLOGIES

In this chapter: 1. issues relating to the data set used in this study will be discussed; 2 . network analysis will be reviewed; 3 . block modeling will be briefly described, and archetypal patterns previously found in block modeling image matrices will be identified; 4 . the three hypotheses presented in Chapter III will be tested; and 5 . the findings of these tests will be presented.

\section{THE DATA SET}

The data were collected in 1981 by a team of researchers from the University of Minnesota, headed by Dr. John O'Brien. This research was funded by the Center for Urban Studies. University of Minnesota, and the Minnesota Board On Aging. The purpose of this study was twofold: 1 . Theoretical interest - trying to use organizational domains to develop a database, relevant to the application of community theory at the level of population of organizations as opposed to populations of individuals; and 2. Applied interest - to determine how senior citizen issues are handled in non-metropolitan communities; of particular interest was the part played by senior citizen centers.

The communities chosen, Albert Lea, Hibbing, Hutchinson, International Falls, Northfield, and Stillwater were chosen so as to 
represent selected characteristics of the non-metropolitan towns in Minnesota. The designated communities were small in size (approximately 10,000 to 20,000 population; free-standing (spatially distinct from other surrounding communities); and dispersed throughout the state (selected so as to lie in at least three different state-level administrative districts).

Because this study was designed to be comparative, it began by taking organizations that were structurally similar; then identifying individuals within these organizations whose access to information was similar. These key informants, selected in each community, were individuals who held equivalent positions in structurally similar organizations. Researchers attempted to interview approximately the same number of key informants in each community. It was also part of the research design that as closely as possible, these informants should occupy the same social position, defined as holding a leadership position in a major local organization.

A list of individuals to be interviewed in each town was developed by the use of public documents to identify the major local organizations in the six specific communities in each of several categories. The research plan called for interviewing only one member of each identified major local organization. The key informant had to be: 1. highly knowledgeable about the inner workings of the organization (i.e., a major executive); 2 . knowledgeable about the connections of that organization with others in the cormunity (had to have been with the organization for five years, and had to have lived in the community for five years) and 3 . knowledgeable about the general pattern of community decision making 
(heavily involved in community affairs). Information regarding the selection of key individuals was provided by the director of the Chamber of Commerce and the United Way director.

The selected organizations represented four categories: 1. private business - banks and businesses that employed the most workers or heid the largest deposits, 2. human service units - the largest and most dominant in each community, 3. voluntary organizations - Chamber of Commerce, three civic clubs (Lions, Rotary, Jaycees), two churches ( largest Lutheran and Catholic), and 4. community leadership units primarily elected bodies(mayor, city council), planning agencies, United Way agencies and newspapers. See Table I. 
TABLE I

TYPES OF ORGANIZATIONS STUDIED IN SIX SMALL MINNESOTA TOWNS

NFD STIL HBG AL HUCH IF TOTAL

$\begin{array}{llllllll}\text { Business } & 6 & 10 & 10 & 7 & 8 & 7 & 48 \\ \text { Financial } & 4 & 3 & 4 & 5 & 3 & 3 & 22 \\ \text { Government } & 2 & 3 & 2 & 3 & 2 & 3 & 15 \\ \text { Health } & 3 & 4 & 4 & 5 & 4 & 4 & 24 \\ \text { Education } & 3 & 1 & 2 & 1 & 1 & 2 & 10 \\ \text { Social Service } & 8 & 6 & 6 & 5 & 7 & 8 & 40 \\ \text { Civic Assoc. } & 3 & 3 & 3 & 3 & 3 & 3 & 18 \\ \text { Church } & 2 & 2 & 2 & 2 & 2 & 2 & 12 \\ \text { Newspaper } & 1 & 1 & 1 & 1 & 1 & 1 & 6 \\ \text { Chamber of Com. } 1 & 1 & 1 & 1 & 1 & 1 & 6 \\ \text { United Way } & 1 & 1 & 1 & 1 & & 4 \\ \text { Foundation } & 1 & & & & & 1 \\ \text { Union } & & & & & & 1 & 1\end{array}$

$\begin{array}{llllllll}\text { Total Number } & 33 & 36 & 36 & 34 & 33 & 35 & 207\end{array}$

Organizations

$\begin{array}{llllllll}\text { Total Number } & 29 & 34 & 28 & 29 & 32 & 31 & 183\end{array}$ Organizational Informants

Interviewed 
Two "types" of data were generated by this study: 1. data about the structural characteristics of organizations ("what" the respondents talked about); and 2. data about structural relations between organizations (through the use of network generators). This second type of data is particularly suited to analys is utilizing network methodology.

\section{NETWORK ANALYSIS}

One way to conceptualize a network is as a problem solving system. Actors become part of a network in order to address issues that cannot be resolved on an individual basis.

Network analysis incorporates two assumptions about social behavior that are significantly different from more traditional approaches. First, any actor typically participates in a social system that involves many other actors. These actors are important references points in each other's decisions. An individual actor's perceptions, beliefs, and actions may be affected and influenced by the number and nature of the relationships that actor has with other members of the social system. (Knoke \& Kuklinski, 1982:9)

Second, it is important to identify and distinguish the various levels in a social system, where "social structure is regularities in the patterns of relations among concrete entities." (White, et al., 1976:733) Relationships may be considered the building blocks of network analysis. Because of its emphasis on the relations that connect social positions within a system, network analysis can detect emergent social phenomena that have no existence at the level of the individual actor. Relational measures identify emergent properties of a social system that 
are impossible to measure by the aggregation of individual member's attributes. Emergent properties have been shown to significantly affect both the behavior of individual network members as well as general system performance. (Knoke \& Kuk1inski, 1982:9-11)

In graph theory, a network is "a relation in which the lines connecting the points have values ascribed to them, which may or may not be numerical." (Mitche11, 1969:3) Mitchell (1969) develops upon this theme by noting that, while mathematical graph theory is not restricted to finite nets, in sociology and anthropology a network is defined as a specific type of relation (non-multiplex) linking an identifiable set of persons, objects, or events. Different types of relations identify different networks, even when imposed on the identical set of nodes. (Knoke \& Kuklinski, 1982:12)

Not only does network analysis deal with the linkages between elements of a network, it must also be concerned with relations that do not exist among the actors that makeup the network. NETWORK STRUCTURE is the specific pattern of present and absent ties among the elements of a network. (Knoke \& Kuklinski, 1982:12)

Regardless of the area to be studied, four elements of a research design shape a researcher's measurement and analysis strategy: the choice of sampling units, the form of relations, the content of the relations, and the level of data analysis. (Knoke \& Kuklinski, 1982:14)

Sampling Units

Knoke and Kuklinski (1982:14-15) identify six basic units, ordered in an increasing scale of size and complexity, that a sample can be drawn from: individuals, groups (formal/informal), complex organizations, 
classes and strata, communities, and nation-states. These authors note that a research design typically involves the investigation of some higher-level system, with some lower-level units specified as nodes. In this thesis, the higher-level systems are each of the six small towns Northfield, Stillwater, Hibbing, Albert Lea, Hutchinson, and International Falls - and the nodes (lower level units) are the individual organizations that make up each community network.

Form of Relations

Relational form refers to properties of linkages between paired actors that exist independently of the relational content. Mitchell (1969:24-29) identifies four of these properties: 1 . DIRECTEDNESS: whether a relationship is one-way or reciprocal, 2. OURABILITY: the length of time a tie endures, 3. INTENSITY: the strength of the link between actors, and 4. FREQUENCY: the numerical count of the number of contacts among the elements of a particular network.

The data set used in this study can only identify "directedness" and "frequency" of the relations involved. It should be noted that it is possible that two or more relations, though quite different in content, may exhibit identical or highly similar forms. This issue will be discussed in greater depth in the section on block modeling.

\section{Content of Relations}

The decision of which specific network linkages to investigate depends upon the individual researcher and the area being studied. No one single type of connection can be designated a priori as the correct 
network to describe a population. Certain substantive problems require that more than one analytically distinct type of relationship be examined. (Berkowitz, 1982; Knoke \& Kuklinski, 1982; White et al., 1976)

Knoke and Kuklinski (1982:15-16) identify several of the more common types of relational content. TRANSACTION RELATIONS refer to the exchange of control over physical or symbolic objects - i.e., gift giving; sales and purchases. COMMUNICATION RELATIONS involve linkages as channels for the transmission of messages within a system. BOUNDARY PENETRATION RELATIONS are ties that consist of constituent subcomponents held in common. An example of this would be boards of directors with over-lapping membership. INSTRUMENTAL RELATIONS refer to linkages that represent attempts to secure valuable goods, services, and information. SENTIMENT RELATIONS are expressions of feelings - affection, admiration, hostility - between actors. AUTHORITY/POWER RELATIONS involve ties that indicate the rights and obligations of actors to issue and obey commands. And finally, KINSHIP/DESCENT RELATIONS are linkages that indicate role relationships among family members.

\section{Levels of Analysis}

In The Rules of Sociological Method (1938), Emile Durkheim distinguished between "individual" and "social" facts. Social facts are properties of group life that cannot be explained with reference to the activities, sensibilities, or characteristics of the individual. For Durkheim, society is a system formed by interacting people. It constitutes a reality in its own right; one with distinctive properties. 
Durkheim's work was the conceptual starting point for much of network analysis. Anthropologists have primarily been concerned with 1 . egocentric networks - where each actor is described by the number, magnitude, and other characteristics of its linkages with other actors; and 2) dyadic networks - where the focus is to explain variation in dyadic relations as a function of joint characteristics of the pair. But there is another level of analysis for network data, one that is closer to Durkheim's conception of society. Many social network analysts agree that there is a level of organization within societies which cannot be adequately understood simply by observing individual behavior; this level of analysis is referred to as the COMPLETE NETWORK or SYSTEM.

In this form of network analysis, a researcher "uses the complete information about patterning of ties among all actors to ascertain the existence of distinct positions or roles within the system and to describe the nature of relations among these positions." (Knoke \& Kuklinski, 1982:17) This is the level of analysis that is employed in this thesis.

In network analysis, one important step is to identify the significant positions within a particular network of relations that link the actors of that system. It is not the actors - whether they are individuals, organizations, or nations - that constitute the social structure; rather it is the observed pattern of relations among the positions or roles occupied by these actors, that make up the social structure of the system. Identification of actors' positions is a necessary, but not sufficient, prerequisite to network analysis. A 
complete analysis is only possible when positions and the relations linking those positions are identified in the network in question.

Positions can also be thought of as analogous to "social roles." They represent subgroups within a network that are defined by a pattern of relations that connect the actors in these roles to one another. A position is consistent and remains, regardless if whether the actor who occupied that position is displaced. For example, if a middle manager in a company is promoted to a vice-presidency, the middle manager position still exists and will continue to do so, no matter who occupies that particular social role.

In network analysis, there are two basic alternatives that are used by an analyst when trying to decide how to identify the positions that make up a complete network and to determine which sub-groups of actors occupy each position. SOCIAL COHESION is the first standard or criterion. Actors are grouped together in a position based on the degree of direct connection with each other on the basis of cohesive bonds. (Burt, 1978) This has also been called "clique analysis."

STRUCTURAL EQUIVALENCE is the second standard used for identifying positions within a network. Actors are grouped into a jointly occupied position on the basis of a common set of linkages to other actors in the system. It is not required that the actors in a position have direct ties to each other. (Knoke \& Kuklinski, 1983; White et al., 1976) Structural equivalence is the criterion employed in this thesis.

Network analysis is useful for describing the external structure of an organization--the patterns of relations and the positions occupied in different networks. Block modeling (White, Boorman, \& Breiger, 1976) is 
a network analytic tool that is useful in studying multiplex networks, The description of network structure based on compounded linkages of more than one type, is one of the strengths of block modeling methodology. (Berkowitz, 1982; Knoke \& Kuklinski, 1982)

\section{BLOCKMODELING}

Blockmodeling involves a self-consistent search procedure which is used to partition a population into sets of actors that are structurally equivalent - BLOCKS. In each data matrix, the rows and columns of each individual are rearranged so that the members of a block are grouped together. Note: the term BLOCK is also used to represent a rectangular submatrix in which a given type of ties from members of one block to members of another block are reported. (White et al., 1976:739)

\section{Fundamental Principles}

White et al. (1976) note that a blockmodel is a hypothesis about a set of data matrices. For each matrix, it specifies which blocks will be zero-blocks when some common partition of the population is imposed upon all the matrices. A blockmodel consists of a square binary matrix, called an IMAGE MATRIX; one for each type of tie. Each image matrix has a row and corresponding column for each block. In this analysis of the six small towns in Minnesota, a four block solution is employed. Therefore, the image matrices will be four rows by four columns.

Several ideas have been identified as basic to block models. (White, et al, 1976:739-740) First, the concept of structural equivalence requires the partitioning of members of the population into distinct sets. Each set is to be treated homogeneously in both its 
internal relations and in its relations to all other sets. Second, it is not the occurrence but the absence of ties between individuals in the subgroup, or set, that is considered the primary indicator of a relation between those sets. Third, many different types of linkages are necessary for an accurate portrayal of the social structure of a population. The social structure of a population or community is multidimensional. Therefore several different types of relationships or linkages need to be examined in order to identify these multiple dimensions. Finally, a model of social structure requires the specification of whether or not a zero block exists, for each pair of sets on each type of tie.

It is important to keep in mind that there is no need for an actor to maintain every tie to all the other actors who belong to his own or any other block. This holds true even if the number of ties between, or within, these blocks are considerable in number. Blockmodeling requires that ties of a given type from any actor in one block to any actor in another be equivalent in structural significance. Sti11, it is not necessary for every actor to choose to mobilize every individual tie all the time. (White 1974; in white et al., 1976:740)

\section{Algorithm}

The computer algorithm employed in this study is CONCOR, which stands for CONvergence of iterated CORrelations. What blockmodeling, in general, and the CONCOR algorithm, in particular, are trying to develop is a generalization of the concept of structural equivalence. This is the basis for treating individuals in the same block as equivalent. 
Various criteria have been developed for assessing the "fit" or validity of specific blockmodels. "Fat" fit requires an identity of the ties between the blocks, on one hand; and the ties between the nodes that are mapped into them, on the other. (Carrington et al., 1979:221) "Lean" fit requires only that elements (nodes) have 0 -valued ties wherever the blocks into which they are mapped have 0-valued ties.

The CONCOR algorithm is a way of starting from raw data and obtaining a partitioning into clusters. These obtained clusters do not always bring out of the data, strict zeroblock structure. Still, the results of CONCOR have been found to be close to the most informative lean-fit block models that have been found through trial-and-error methods. CONCOR may be interpreted as a search procedure for lean fit blockmodels.

The network data, as analyzed in my thesis, converges on columns rather than rows. This follows the emphasis of Breiger, Boorman, and Arabie (1975) and Arabie and Boorman (1982). Given a choice between columns or rows, columns are preferred on the basis of being the "best" in a "worst possible case" scenario. If a single actor reports erroneous linkages to all the members of the group (therefore that actor's role in the sociomatrix is "noise"), then a blocking based on rows will yield an inaccurate result for the individual, and for the block that should have contained that actor. However, if the blocking is done on columns, then the actor will have contributed a much smaller error to the column vectors (i.e., one erroneous entry per vector).

It is important to note, that each level of blockmodeling refinement will produce its own image matrices. As the degree of refinement 
increases, the successive image matrices more and more closely approximates the original network. In the limit, where $n$ blocks are used, each actor occupies a single block, and the so-called "images" are simply the original data. At the opposite extreme is a single block comprising the entire population. There is nothing to be learned by mapping the data onto the image matrices.

It follows that the problem of blockmodeling is the matter of choosing which level or levels of refinement generated through CONCOR provide the optimal degree of aggregation for understanding and interpreting the data. A four block solution is employed in the data analysis pertaining to this study. While a two block solution is not difficult to obtain, it does not lend itself to a "rich" interpretation of all the information available in the data.

One of the areas of interest in blockmodeling is networks with multiple types of relations. Several researchers have noted that the best results (most interesting interpretations) are obtained when a blockmodel is formed by the juxtaposition of many types of contrasting relations in the same "stack." (Arabie \& Boorman, 1982; Berkowitz, 1982; White et al., 1976) These authors also emphasize the desirability of displaying maximal relational contrast. (Example: symmetric vs. asymmetric ties; positive sentiment vs. antagonism). One of the strengths of the data set utilized in this study is the variety of relational content "types," as well as different forms of relations that are present.

One way to categorize block models is through comparison of the image matrix with the image matrices of previously identified ideal-type block models. 


\section{Patterns in Image Matrices}

White et al. (1976:741-744) identified specific image matrices for certain "archetypal" block models. Several of these are particularly relevant to this study. These archetypal image matrix patterns will be used to test for the presence of predicted inter-organizational relationships, as put forth in the hypotheses presented in Chapter II, in the empirical data.

"HANGERS ON"
A. 11111
B. 10000
10000
$\begin{array}{llll}1 & 0 & 0 & 0\end{array}$
$\begin{array}{llll}1 & 0 & 0 & 0\end{array}$
$\begin{array}{llll}1 & 0 & 0 & 0\end{array}$
$\begin{array}{llll}1 & 0 & 0 & 0\end{array}$
$\begin{array}{llll}1 & 1 & 1 & 1\end{array}$

Both of these patterns came up repeatedly in the White studies. Pattern $A$ is identified as the "Hangers On" pattern. This shows differential standing, with block 1 as the "top" of an overall deference structure. A clear distinction is visible between the "core" and the "periphery."

Pattern $B$ is identified as an ideal-type hierarchy. Ties of deference exist within block four, as well as from the lower to higher blocks in the hierarchy.

\section{REFLEXIVITY}

C. $\begin{array}{llll}0 & 1 & 0 & 0\end{array}$

$\begin{array}{llll}1 & 0 & 0 & 0\end{array}$

$\begin{array}{llll}0 & 0 & 0 & 0\end{array}$

$\begin{array}{llll}0 & 0 & 0 & 0\end{array}$

\section{SYMMETRY}

D. $0 \begin{array}{llll}0 & 0 & 0 & 0\end{array}$

$\begin{array}{llll}0 & 0 & 0 & 0\end{array}$

$\begin{array}{llll}0 & 0 & 1 & 0\end{array}$

$\begin{array}{llll}0 & 0 & 0 & 1\end{array}$ 
The archetypal pattern in patterns $C$ and $D$ (between the "I's") could be found in any part of the image matrix. White calls $C$ pure "reflexivity," and D pure "symmetry." If the relationship described by the image matrix is positive, then this pattern shows affiliation, cooperation, or positive binding. If the relationship described by the image matrix is negative, the pattern shows competition, hostility, or animosity.

\section{CLIQUES}
E. 11100
F. $0 \begin{array}{lllll}0 & 0 & 0 & 0\end{array}$
1100
$\begin{array}{llll}0 & 0 & 0 & 0\end{array}$
$\begin{array}{llll}0 & 0 & 0 & 0\end{array}$
$\begin{array}{llll}0 & 0 & 1 & 1\end{array}$
$\begin{array}{llll}0 & 0 & 0 & 0\end{array}$
$\begin{array}{llll}0 & 0 & 1 & 1\end{array}$

The ideal-type image matrix pattern shown in patterns $E$ and $F$ identifies a clique from the remaining isolated individuals. If the relationship described by this image matrix is negative, then this pattern shows a concentration of hostility within a particular sub-set.

These ideal-type image matrices will serve as the standards for the hypothesis testing in the next section. By comparing these patterns with the patterns developed by blockmodeling the data, it will be possible to determine if the inter-organizational relationships, predicted by the specific hypotheses, are actually present in the empirical data.

In order to facilitate the identification of these ideal-type patterns in the empirical data, the four block structure of each image matrix is arranged in the following standardized order: BLOCK 1 financial institutions, BLOCK 2 - businesses, BLOCK 3 - government 
organizations, and BLOCK 4 - social service organizations. (See APPENDIX A: TABLE XVI for the decision rules that are the basis for this standardized ordering)

\section{TESTS OF HYPOTHESES}

In this study, seven different inter-organizational relations are examined: 1. "Pass funds to" (transaction relation), 2. "Receive funds from" (transaction relation), 3. "Assign personnel to cooperate on economic developments" (boundary penetration relation), 4. "Assign personnel to cooperate on human services planning" (boundary penetration relation), 5. "Have letters of agreement/contracts with" (instrumental relation), 6. "Their evaluation is critical to your organization's self-image" (sentiment relation), 7. "Send personnel to for services and products" (instrumental relation).

The interactional pattern of organizations in a community network, in terms of a specific relationship, is indicated by the configuration present in the image matrix whose number corresponds with the number of the relationship. For example, IMAGE MATRIX 1 represents the relationship "Pass funds to."

TABLES II, III, IV, V, VI, VII, and VIII show which of these predicted relationships are present when the organizations are partitioned based on the block modeling of the empirical data, as well as the individual block densities for each specific matrix for each community.

If the IMAGE MATRIX in question has "l's" in all the positions where the ideal-type, predicted relationship has "l's," the relationship is 
TABLE I I

AN ACROSS-COMMUNITY COMPARISON OF IMAGE MATRIX I AND DENSITY TABLES COMMUNITY IMAGE MATRIX DENSITY TABLES

NFD

$\begin{array}{llll}1 & 1 & 1 & 1 \\ 1 & 1 & 0 & 0 \\ 1 & 0 & 0 & 0 \\ 0 & 0 & 0 & 0\end{array}$

$.500 \quad .440 \quad .400 \quad .440$

$.280 \quad .200 \quad .100 \quad .140$

$\begin{array}{llll}.300 & .063 & .089 & .150\end{array}$

$.140 \quad .030 \quad .100 \quad .089$

matrix density $=.179$

\begin{tabular}{lllllllll}
\hline STIL & 1 & 1 & 1 & 1 & .300 & .236 & .187 & .233 \\
& 1 & 1 & 0 & 1 & .582 & .173 & .084 & .167 \\
& 1 & 0 & 0 & 0 & .429 & .058 & .093 & .012 \\
1 & 0 & 0 & 0 & & .033 & .015 & .083 & .067
\end{tabular}

matrix density $=.148$

\begin{tabular}{|c|c|c|c|c|c|}
\hline$H B G$ & $\begin{array}{llll}1 & 1 & 0 & 1 \\
1 & 1 & 0 & 0 \\
1 & 0 & 0 & 0 \\
1 & 0 & 0 & 0\end{array}$ & $\begin{array}{r}.350 \\
.340 \\
.277 \\
.375 \\
\text { mat } \\
\end{array}$ & $\begin{array}{r}.160 \\
.244 \\
.008 \\
.000 \\
. j \times d e \\
\end{array}$ & $\begin{array}{l}.138 \\
.115 \\
.038 \\
.115 \\
\text { isity }\end{array}$ & $\begin{array}{r}.400 \\
.071 \\
.077 \\
.071 \\
=.139 \\
\end{array}$ \\
\hline$A L$ & $\begin{array}{llll}1 & 0 & 0 & 1 \\
1 & 0 & 0 & 1 \\
1 & 0 & 1 & 0 \\
1 & 0 & 0 & 1\end{array}$ & $\begin{array}{r}.200 \\
.133 \\
.271 \\
.400 \\
\text { mat } \\
\end{array}$ & $\begin{array}{l}.050 \\
.000 \\
.000 \\
.030 \\
.0 \mathrm{~d} 6 \\
\end{array}$ & $\begin{array}{l}.042 \\
.050 \\
.268 \\
.050 \\
\text { isity }\end{array}$ & $\begin{array}{r}.117 \\
.200 \\
.038 \\
.133 \\
=.111 \\
\end{array}$ \\
\hline $\mathrm{HUCH}$ & $\begin{array}{llll}0 & 1 & 0 & 1 \\
1 & 1 & 0 & 1 \\
0 & 0 & 1 & 0 \\
0 & 0 & 0 & 1\end{array}$ & $\begin{array}{r}.084 \\
.344 \\
.107 \\
.063 \\
\quad \text { mat } \\
\end{array}$ & $\begin{array}{r}.188 \\
.189 \\
.131 \\
.125 \\
.1 \times d e \\
\end{array}$ & $\begin{array}{l}.089 \\
.024 \\
.333 \\
.024 \\
\text { isity }\end{array}$ & $\begin{array}{r}.271 \\
.181 \\
.119 \\
.300 \\
=.163 \\
\end{array}$ \\
\hline IF & $\begin{array}{llll}1 & 1 & 1 & 1 \\
0 & 1 & 1 & 0 \\
0 & 1 & 0 & 0 \\
0 & 1 & 0 & 0\end{array}$ & $\begin{array}{r}.667 \\
.139 \\
.111 \\
.019 \\
\text { mat }\end{array}$ & $\begin{array}{l}.417 \\
.431 \\
.259 \\
.282 \\
. i x d \epsilon\end{array}$ & $\begin{array}{l}.278 \\
.198 \\
.056 \\
.043 \\
\text { isity }\end{array}$ & $\begin{array}{r}.269 \\
.094 \\
.171 \\
.173 \\
=.189 \\
\end{array}$ \\
\hline
\end{tabular}


TABLE I I I

AN ACROSS-COMMUNITY COMPARISON OF IMAGE MATRIX II AND DENSITY TABLES

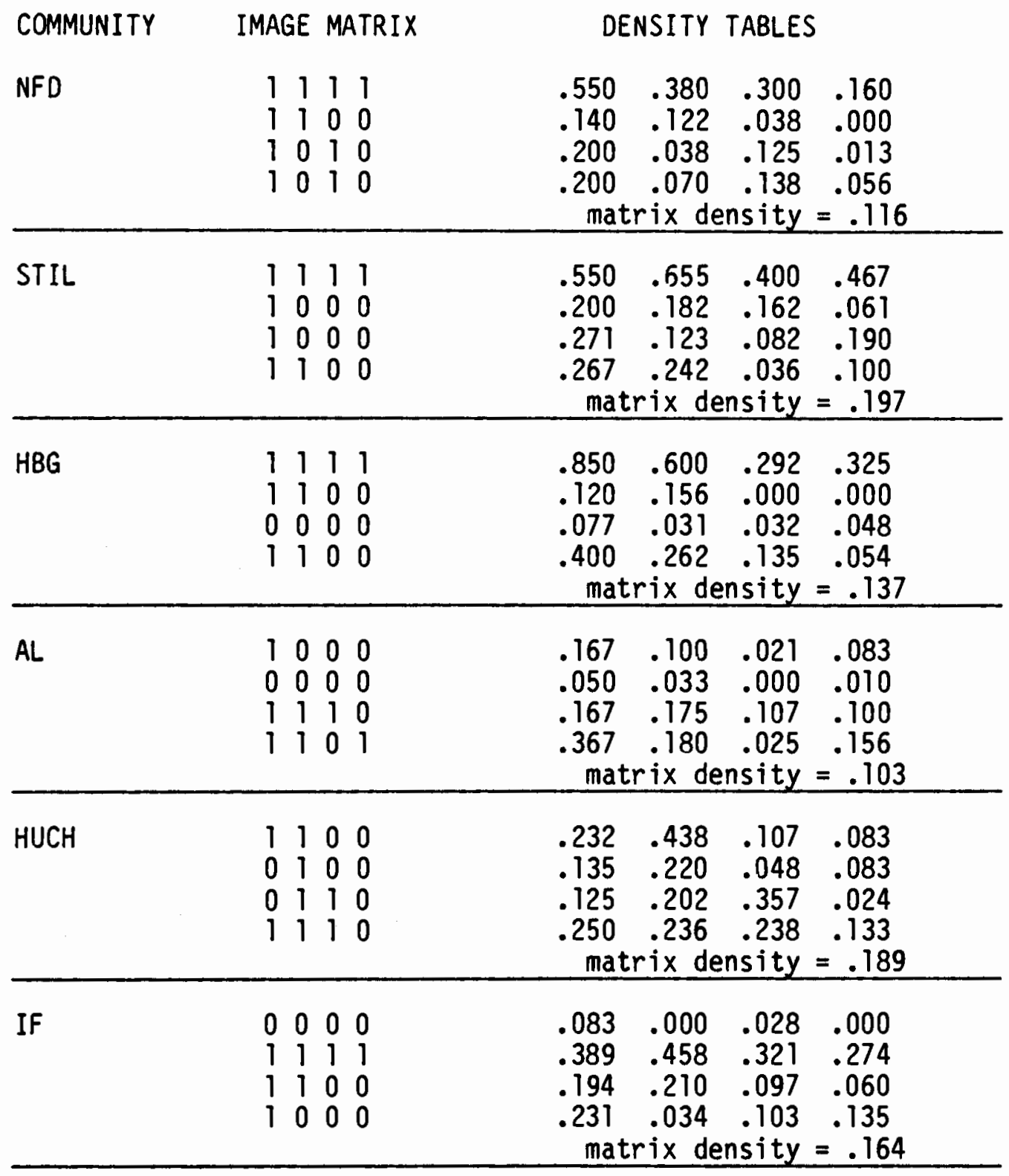


TABLE IV

AN ACROSS-COMMUNITY COMPARISON OF IMAGE MATRIX III AND DENSITY TABLES COMMUNITY IMAGE MATRIX DENSITY TABLES

\begin{tabular}{|c|c|c|c|c|}
\hline NFD & $\begin{array}{llll}0 & 0 & 0 & 0 \\
0 & 1 & 0 & 0 \\
1 & 1 & 1 & 0 \\
1 & 0 & 1 & 1\end{array}$ & $\begin{array}{ll}.000 & .040 \\
.040 & .100 \\
.275 & .262 \\
.120 & .010 \\
\text { matrix der }\end{array}$ & $\begin{array}{r}.050 \\
.025 \\
.107 \\
.112 \\
\text { sity } \\
\end{array}$ & $\begin{array}{r}.020 \\
.010 \\
.075 \\
.144 \\
=.087 \\
\end{array}$ \\
\hline STIL & $\begin{array}{llll}1 & 0 & 0 & 1 \\
0 & 0 & 1 & 1 \\
0 & 0 & 0 & 0 \\
1 & 1 & 1 & 1\end{array}$ & $\begin{array}{ll}.250 & .073 \\
.073 & .073 \\
.000 & .000 \\
.167 & .167 \\
\text { matrix der }\end{array}$ & $\begin{array}{l}.071 \\
.091 \\
.027 \\
.179 \\
\text { sity } \\
\end{array}$ & $\begin{array}{r}.333 \\
.303 \\
.024 \\
.233 \\
=.091 \\
\end{array}$ \\
\hline HBG & $\begin{array}{llll}1 & 1 & 1 & 1 \\
0 & 0 & 0 & 1 \\
0 & 1 & 0 & 1 \\
1 & 0 & 0 & 0\end{array}$ & $\begin{array}{cc}.350 & .100 \\
.040 & .000 \\
.031 & .077 \\
.125 & .063 \\
\text { matrix der }\end{array}$ & $\begin{array}{l}.123 \\
.023 \\
.058 \\
.058 \\
\text { isity }\end{array}$ & $\begin{array}{r}.300 \\
.087 \\
.115 \\
.054 \\
. .076 \\
\end{array}$ \\
\hline$A L$ & $\begin{array}{llll}1 & 0 & 1 & 0 \\
1 & 0 & 1 & 0 \\
1 & 0 & 1 & 1 \\
0 & 0 & 0 & 0\end{array}$ & $\begin{array}{ll}.067 & .033 \\
.083 & .011 \\
.083 & .025 \\
.017 & .000 \\
\text { matrix den } & \\
\end{array}$ & $\begin{array}{l}.042 \\
.063 \\
.179 \\
.000 \\
\text { isity }\end{array}$ & $\begin{array}{r}.033 \\
.030 \\
.050 \\
.011 \\
. .039 \\
\end{array}$ \\
\hline $\mathrm{HUCH}$ & $\begin{array}{llll}0 & 0 & 0 & 1 \\
1 & 0 & 0 & 0 \\
1 & 0 & 1 & 0 \\
1 & 1 & 1 & 1\end{array}$ & $\begin{array}{cc}.036 & .063 \\
.146 & .045 \\
.089 & .036 \\
.167 & .167 \\
\text { matrix den } \\
\end{array}$ & $\begin{array}{l}.036 \\
.036 \\
.143 \\
.119 \\
\text { sity }\end{array}$ & $\begin{array}{r}.104 \\
.056 \\
.048 \\
.200 \\
. .084 \\
\end{array}$ \\
\hline If & $\begin{array}{llll}1 & 0 & 1 & 0 \\
1 & 1 & 1 & 0 \\
0 & 0 & 0 & 0 \\
0 & 0 & 1 & 1\end{array}$ & $\begin{array}{cc}.333 & .056 \\
.167 & .125 \\
.056 & .025 \\
.000 & .051 \\
\text { matrix den }\end{array}$ & $\begin{array}{l}.167 \\
.074 \\
.014 \\
.068 \\
\text { isity }\end{array}$ & $\begin{array}{l}.058 \\
.051 \\
.026 \\
.0109 \\
=.068 \\
\end{array}$ \\
\hline
\end{tabular}


TABLE $V$

AN ACROSS-COMMUNITY COMPARISON OF IMAGE MATRIX IV AND DENSITY TABLES COMMUNITY IMAGE MATRIX

DENSITY TABLES

\begin{tabular}{|c|c|c|c|c|}
\hline NFD & $\begin{array}{llll}0 & 0 & 0 & 0 \\
0 & 0 & 0 & 0 \\
0 & 1 & 1 & 1 \\
0 & 0 & 1 & 1\end{array}$ & $\begin{array}{cc}.000 & .080 \\
.040 & .033 \\
.125 & .188 \\
.020 & .070 \\
\text { matr } \mathbf{i x} \text { den } \\
\end{array}$ & $\begin{array}{r}.100 \\
.000 \\
.250 \\
.275 \\
\text { isity } \\
\end{array}$ & $\begin{array}{r}.040 \\
.040 \\
.313 \\
.278 \\
=.126 \\
\end{array}$ \\
\hline STIL & $\begin{array}{llll}1 & 0 & 1 & 1 \\
0 & 0 & 0 & 1 \\
0 & 0 & 1 & 0 \\
0 & 0 & 1 & 1\end{array}$ & $\begin{array}{cc}.300 & .145 \\
.073 & .000 \\
.114 & .032 \\
.133 & .091 \\
\text { matrix den }\end{array}$ & $\begin{array}{l}.429 \\
.026 \\
.286 \\
.226 \\
\text { isity } \\
\end{array}$ & $\begin{array}{r}.467 \\
.273 \\
.143 \\
.333 \\
=.159 \\
\end{array}$ \\
\hline HBG & $\begin{array}{llll}1 & 0 & 1 & 0 \\
0 & 0 & 0 & 0 \\
0 & 0 & 1 & 0 \\
0 & 0 & 1 & 1\end{array}$ & $\begin{array}{cc}.150 & .060 \\
.020 & .000 \\
.015 & .031 \\
.125 & .087 \\
\text { matrix den }\end{array}$ & $\begin{array}{r}.262 \\
.023 \\
.212 \\
.288 \\
\text { isity }\end{array}$ & $\begin{array}{r}.550 \\
.112 \\
.106 \\
.161 \\
=.125 \\
\end{array}$ \\
\hline AL & $\begin{array}{llll}1 & 0 & 1 & 1 \\
0 & 0 & 0 & 0 \\
0 & 0 & 1 & 1 \\
0 & 0 & 0 & 1\end{array}$ & $\begin{array}{cc}.167 & .067 \\
.033 & .033 \\
.000 & .013 \\
.000 & .020 \\
\text { matrix den }\end{array}$ & $\begin{array}{r}.125 \\
.075 \\
.411 \\
.013 \\
\text { isity } \\
\end{array}$ & $\begin{array}{r}.183 \\
.040 \\
.250 \\
.156 \\
=.091 \\
\end{array}$ \\
\hline HUCH & $\begin{array}{llll}1 & 0 & 1 & 1 \\
0 & 0 & 0 & 0 \\
0 & 0 & 1 & 1 \\
1 & 1 & 1 & 1\end{array}$ & $\begin{array}{cc}.232 & .021 \\
.083 & .008 \\
.089 & .071 \\
.292 & .181 \\
\text { matrix den }\end{array}$ & $\begin{array}{r}.268 \\
.048 \\
.595 \\
.310 \\
\text { isity }\end{array}$ & $\begin{array}{r}.271 \\
.069 \\
.310 \\
.567 \\
=.158 \\
\end{array}$ \\
\hline IF & $\begin{array}{llll}1 & 0 & 1 & 1 \\
0 & 0 & 0 & 0 \\
0 & 0 & 0 & 1 \\
1 & 0 & 0 & 1\end{array}$ & $\begin{array}{cc}.417 & .028 \\
.000 & .042 \\
.111 & .062 \\
.115 & .000 \\
\text { matrix den }\end{array}$ & $\begin{array}{l}.278 \\
.086 \\
.069 \\
.085 \\
\text { isity }\end{array}$ & $\begin{array}{r}.154 \\
.068 \\
.137 \\
.314 \\
=.115 \\
\end{array}$ \\
\hline
\end{tabular}


TABLE VI

AN ACROSS-COMMUNITY COMPARISON OF IMAGE MATRIX $\checkmark$ AND DENSITY TABLES COMMUNITY IMAGE MATRIX

DENSITY TABLES

NFD

$\begin{array}{lllll}0 & 0 & 1 & 1\end{array}$

$\begin{array}{lllll}0 & 0 & 0 & 0\end{array}$

$\begin{array}{llll}1 & 0 & 1 & 1\end{array}$

$\begin{array}{llll}1 & 0 & 1 & 1\end{array}$

$\begin{array}{llll}.000 & .000 \quad .100 \quad .040\end{array}$

$.000 \quad .000 \quad .000 \quad .000$

$\begin{array}{llll}.150 & .000 & .036 & .038\end{array}$

$\begin{array}{llll}.040 \quad .000 \quad .112 & .089\end{array}$

matrix density $=.034$

\begin{tabular}{llllllllll}
\hline STIL & 1 & 1 & 1 & 0 & & .050 & .036 & .057 & .000 \\
& 1 & 0 & 0 & 0 & & .055 & .009 & .019 & .015 \\
& 1 & 0 & 1 & 0 & & .057 & .013 & .099 & .012 \\
& 0 & 0 & 0 & 0 & & .033 & .015 & .012 & .000 \\
& & & & & & \\
& matrix density & $=.034$ \\
\hline
\end{tabular}

HBG

$\begin{array}{llll}1 & 1 & 0 & 0 \\ 1 & 1 & 0 & 0\end{array}$

$\begin{array}{llll}.400 & .120 & .046 & .025\end{array}$

$\begin{array}{llll}0 & 0 & 1 & 1\end{array}$

$\begin{array}{llll}.200 & .200 & .031 & .038\end{array}$

1100

$\begin{array}{llll}.015 & .015 & .0309 & .038\end{array}$

$\begin{array}{llll}.225 & .125 & .019 & .036\end{array}$

matrix density $=.085$

\begin{tabular}{|c|c|c|c|c|c|}
\hline AL & $\begin{array}{llll}0 & 0 & 0 & 0 \\
0 & 0 & 0 & 0 \\
1 & 1 & 1 & 1 \\
1 & 0 & 0 & 1\end{array}$ & $\begin{array}{c}.000 \\
.033 \\
.354 \\
.083 \\
\text { mat } \\
\end{array}$ & $\begin{array}{l}.017 \\
.000 \\
.063 \\
.000 \\
\text { ix der }\end{array}$ & $\begin{array}{r}.021 \\
.013 \\
.089 \\
.025 \\
\text { nsity }\end{array}$ & $\begin{array}{l}.017 \\
.010 \\
.112 \\
.067 \\
=.050 \\
\end{array}$ \\
\hline $\mathrm{HUCH}$ & $\begin{array}{llll}0 & 0 & 1 & 1 \\
0 & 0 & 0 & 0 \\
0 & 0 & 1 & 0 \\
1 & 1 & 1 & 1\end{array}$ & $\begin{array}{c}.036 \\
.000 \\
.054 \\
.104 \\
\text { mat }\end{array}$ & $\begin{array}{l}.073 \\
.023 \\
.024 \\
.097 \\
. i x \text { der }\end{array}$ & $\begin{array}{r}.161 \\
.000 \\
.429 \\
.190 \\
\text { nsity }\end{array}$ & $\begin{array}{r}.188 \\
.014 \\
.048 \\
.133 \\
=.076 \\
\end{array}$ \\
\hline IF & $\begin{array}{llll}1 & 1 & 0 & 0 \\
0 & 0 & 0 & 0 \\
1 & 0 & 0 & 1 \\
1 & 1 & 0 & 1\end{array}$ & $\begin{array}{r}.167 \\
.083 \\
.167 \\
.173 \\
\text { mat }\end{array}$ & $\begin{array}{l}.167 \\
.111 \\
.123 \\
.137 \\
.1 \times \text { der }\end{array}$ & $\begin{array}{r}.111 \\
.012 \\
.028 \\
.068 \\
\text { nsity }\end{array}$ & $\begin{array}{r}.019 \\
.043 \\
.162 \\
.372 \\
=.133\end{array}$ \\
\hline
\end{tabular}


TABLE VII

AN ACROSS-COMMUNITY COMPARISON OF IMAGE MATRIX VI AND DENSITY TABLES COMMUNITY IMAGE MATRIX

DENSITY TABLES

NFD

$\begin{array}{llll}1 & 0 & 1 & 0 \\ 1 & 1 & 1 & 0 \\ 1 & 1 & 1 & 0 \\ 0 & 0 & 1 & 0\end{array}$

$\begin{array}{llll}.250 & .220 & .350 & .100\end{array}$

$\begin{array}{llll}.320 & .278 & .275 & .200\end{array}$

$\begin{array}{llll}.325 & .287 & .321 & .125\end{array}$

$\begin{array}{llll}.140 \quad .130 & .250 \quad .189\end{array}$

matrix density $=.226$

STIL

$\begin{array}{llll}1 & 1 & 1 & 1 \\ 0 & 0 & 0 & 1\end{array}$

$\begin{array}{llll}0 & 0 & 0 & 1\end{array}$

$\begin{array}{llll}0 & 0 & 0 & 0\end{array}$

$\begin{array}{llll}1 & 0 & 0 & 1\end{array}$

$\begin{array}{llll}.450 & .636 & .500 & .400\end{array}$

$\begin{array}{llll}.164 & .200 & .110 & .212\end{array}$

$\begin{array}{llll}.186 & .078 & .143 & .131\end{array}$

$\begin{array}{llll}.233 & .167 \quad .190 & .267\end{array}$

matrix density $=.204$

\begin{tabular}{|c|c|c|c|c|c|}
\hline HBG & $\begin{array}{llll}1 & 1 & 1 & 1 \\
1 & 1 & 0 & 1 \\
0 & 0 & 0 & 0 \\
1 & 1 & 0 & 0\end{array}$ & $\begin{array}{r}.450 \\
.180 \\
.077 \\
.300 \\
\text { mat }\end{array}$ & $\begin{array}{r}.420 \\
.167 \\
.015 \\
.162 \\
\text { rix de }\end{array}$ & $\begin{array}{l}.323 \\
.100 \\
.141 \\
.077 \\
\text { isity }\end{array}$ & $\begin{array}{l}.375 \\
.200 \\
.125 \\
.125 \\
=.160\end{array}$ \\
\hline
\end{tabular}

AL

$\begin{array}{llll}0 & 0 & 0 & 0 \\ 0 & 0 & 0 & 0 \\ 1 & 0 & 1 & 1 \\ 0 & 0 & 1 & 1\end{array}$

$\begin{array}{llll}.033 & .000 & .063 & .033\end{array}$

$\begin{array}{llll}.067 & .011 & .038 & .060\end{array}$

$\begin{array}{llll}.146 & .025 & .304 & .162\end{array}$

$\begin{array}{llll}.100 & .070 & .213 & .344\end{array}$

matrix density $=.107$

$\mathrm{HUCH}$

1100

$\begin{array}{llll}0 & 0 & 0 & 0\end{array}$

$\begin{array}{llll}.304 & .292 & .089 & .167\end{array}$

$\begin{array}{llll}1 & 1 & 1 & 1\end{array}$

$\begin{array}{llll}.208 & .182 & .095 & .111\end{array}$

1000

$\begin{array}{llll}.339 & .310 & .643 & .405\end{array}$

$\begin{array}{llll}.250 & .208 & .167 & .233\end{array}$

matrix density $=.235$

IF $\quad \begin{array}{llll}1 & 1 & 1 & 1 \\ 1 & 1 & 1 & 0 \\ 0 & 0 & 0 & 0 \\ 0 & 0 & 0 & 1\end{array}$

$\begin{array}{llll}.417 & .444 & .611 & .462\end{array}$

$\begin{array}{llll}.472 & .369 & .333 & .231\end{array}$

$\begin{array}{llll}.194 & .198 & .181 & .197\end{array}$

$\begin{array}{llll}.385 & .085 & .327 & .231\end{array}$

matrix density $=.280$ 
TABLE VIII

AN ACROSS COMMUNITY COMPARISON OF IMAGE MATRIX VII AND DENSITY TABLES COMMUNITY IMAGE MATRIX DENSITY TABLES

\begin{tabular}{|c|c|c|c|c|}
\hline NFD & $\begin{array}{llll}0 & 1 & 1 & 1 \\
0 & 1 & 0 & 0 \\
1 & 0 & 1 & 1 \\
0 & 0 & 0 & 1\end{array}$ & $\begin{array}{ll}.050 & .340 \\
.120 & .211 \\
.250 & .050 \\
.120 & .040 \\
\text { matrix der }\end{array}$ & $\begin{array}{r}.275 \\
.150 \\
.214 \\
.162 \\
\text { nsity }=\end{array}$ & $\begin{array}{r}.420 \\
.030 \\
.225 \\
.223 \\
=. .169 \\
\end{array}$ \\
\hline STIL & $\begin{array}{llll}0 & 0 & 1 & 1 \\
0 & 0 & 0 & 0 \\
1 & 0 & 1 & 1 \\
1 & 1 & 1 & 1\end{array}$ & $\begin{array}{cc}.150 & .091 \\
.018 & .118 \\
.186 & .104 \\
.300 & .197 \\
\text { matrix den }\end{array}$ & $\begin{array}{r}.229 \\
.104 \\
.291 \\
.190 \\
\text { nsity }\end{array}$ & $\begin{array}{r}.167 \\
.106 \\
.167 \\
.200 \\
. .163 \\
\end{array}$ \\
\hline HBG & $\begin{array}{llll}0 & 0 & 0 & 0 \\
0 & 1 & 0 & 0 \\
0 & 0 & 1 & 1 \\
1 & 0 & 1 & 1\end{array}$ & $\begin{array}{cc}.000 & .000 \\
.060 & .133 \\
.062 & .023 \\
.250 & .035 \\
\text { matrix den } \\
\end{array}$ & $\begin{array}{r}.062 \\
.015 \\
.160 \\
.240 \\
\text { nsity }\end{array}$ & $\begin{array}{l}.025 \\
.025 \\
.096 \\
.125 \\
=.088 \\
\end{array}$ \\
\hline$A L$ & $\begin{array}{llll}0 & 0 & 0 & 0 \\
1 & 0 & 0 & 0 \\
1 & 0 & 1 & 1 \\
0 & 1 & 1 & 1\end{array}$ & $\begin{array}{cc}.000 & .100 \\
.133 & .078 \\
.167 & .000 \\
.100 & .140 \\
\text { matrix } & \text { den } \\
\end{array}$ & $\begin{array}{r}.063 \\
.050 \\
.304 \\
.150 \\
\text { nsity } \\
\end{array}$ & $\begin{array}{r}.017 \\
.030 \\
.275 \\
.356 \\
. .127 \\
\end{array}$ \\
\hline $\mathrm{HUCH}$ & $\begin{array}{llll}1 & 0 & 1 & 1 \\
0 & 0 & 0 & 0 \\
0 & 0 & 1 & 0 \\
1 & 1 & 1 & 1\end{array}$ & $\begin{array}{cc}.214 & .104 \\
.063 & .126 \\
.125 & .060 \\
.229 & .222 \\
\text { matrix den }\end{array}$ & $\begin{array}{l}.268 \\
.119 \\
.452 \\
.262 \\
\text { nsity }\end{array}$ & $\begin{array}{l}.292 \\
.111 \\
.119 \\
.300 \\
=.163 \\
\end{array}$ \\
\hline IF & $\begin{array}{llll}1 & 1 & 0 & 1 \\
0 & 1 & 0 & 0 \\
0 & 1 & 0 & 0 \\
1 & 0 & 0 & 1\end{array}$ & $\begin{array}{cc}.250 & .222 \\
.111 & .205 \\
.083 & .136 \\
.192 & .068 \\
\text { matrix den }\end{array}$ & $\begin{array}{l}.056 \\
.099 \\
.042 \\
.051 \\
\text { isity }=\end{array}$ & $\begin{array}{l}.173 \\
.051 \\
.077 \\
.256 \\
. .122\end{array}$ \\
\hline
\end{tabular}


identified as PRESENT. If one or more of the linkages identified as "l's" in the ideal-type, predicted relationship are identified as "0's" in the IMAGE MATRIX in question, the next step will be to consult the TABLE OF DENSITIES for that matrix.

KEY: Density of ties in a block $=y$

Average density of ties in a matrix $=x$

a) if $y$ is greater than or equal to $.75 x$ = VERY CLOSE

b) if $y$ is greater than or equal to $.5 x=$ CLOSE

c) if $y$ is greater than or equal to $.25 x=$ present but weak

d) if $y$ is less than $.25 x=$ not present

\section{Resource Dependence}

HYPOTHESIS I: The greater the dependence on external-to-the-organization sources of funding by the members of an organizational network, the more dominant the positions of financial-resources controlling organizations. (Input)

This relationship would be shown to be present, by the identification of the "Hangers On" pattern in both IMAGE MATRICES I and II.

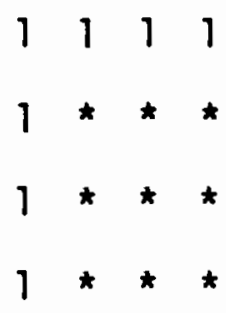

HYPOTHESIS I, based on the RESOURCE DEPENDENCE typology, predicted relationships identifying the dominance of financial organizations. The predicted relationship for MATRICES I and II are present in 3 towns NFD, STIL, and HBG. These are strong relationships, exhibiting a high 
density of linkages and a definite "core-periphery" relationship between the "financial/information services" and the rest of the network.

In the other 3 towns - AL, HUCH, and IF - this relationship is not present in as strong and clear a form as in NFD, STIL, or HBG. In AL, the "core-periphery" pattern is present, but in a weaker form than in previous 3 towns.

MATRIX I: 2 ties missing = present but weak MATRIX II: 4 ties missing: 1 = VERY CLOSE, 1 = CLOSE, 1 = present but weak, and $1=$ not present

In HUCH, BLOCK 2 is closer to the "core" position, as seen in the first 4 towns than BLOCK 1. In this town, BUSINESS ORGANIZATIONS and FINANCIAL INSTITUTIONS are grouped together in BLOCK 2. The structure of the "financial dominance" inter-organization relational network may be different from the other communities for another reason, the presence of a major national corporation - 3M - in this community. Financial exchanges seem to center around the business "block," with the exception of the local government which sends and receives funds primarily within its own group (block 3 ).

In IF, BLOCK 1 is made up of divisions of a major national corporation - The Boise Company. This block is central to MATRIX I, as far as "passing money." It is not central to MATRIX II as far as "receiving money." If is a "company town"; therefore the company (Boise) directs funds within the community to pay for the needs and services supplied to workers. Funding for this company, however, comes from outside the community. When this is considered, BLOCK 2 (which contains the banks and the non-Boise businesses), becomes the "core" of a 
"core-periphery" organizational network.

RESULTS OF TESTING HYPOTHESIS I: From a RESOURCE DEPENDENCE perspective, the predicted relationships in MATRICES I and II are strongly present in four of the six towns. Overall, this relationship is present in both MATRICES I and II.

\section{$\underline{K a t z}$ and Kahn}

HYPOTHESIS II: The greater the similarity between organizational throughputs, the greater the probability of inter-organizational cooperation. (Throughput)

This would be indicated by the organizations occupying positions in the organizational network that would show reciprocal ties. This relationship would be shown to be present by the identification of either the "pure symmetry" or "pure reflexivity" patterns between BLOCK 1 and BLOCK 2 in IMAGE MATRIX III; or between BLOCK 3 and BLOCK 4 in IMAGE MATRIX IV.

Matrix III
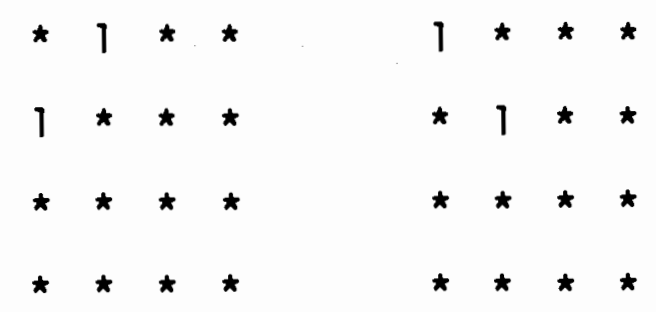

Matrix IV
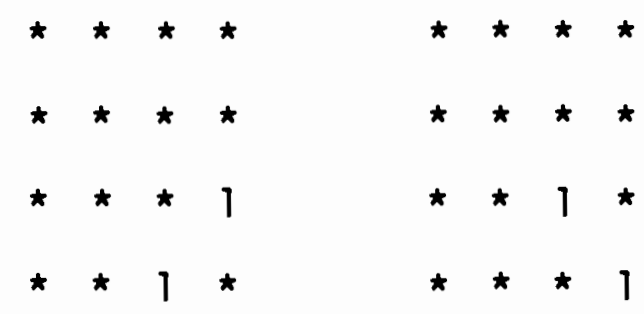
KATZ ANO KAHN predicted relationships identifying 2 different "types" of cooperation. "CONTINGENT COOPERATION", is represented through "Cooperate on economic development", the relationship considered in MATRIX III. This type of cooperation predicts reciprocal ties between BLOCKS 1 and 2. This relationship is strongly present in one town - IF. NFD: 1 tie missing $=$ not present

STIL: 1 tie missing $=$ not present

$H B G: 1$ tie missing = present but weak

$A L: 1$ tie missing $=$ CLOSE

HUCH: 2 ties missing = present but weak

IF : 1 tie missing = present but weak

A second type of cooperation, "MANDATED COOPERATION," is represented through "Cooperate on human services planning," the relationship considered in MATRIX IV. This type of cooperation predicts reciprocal ties between BLOCKS 3 and 4 . This relationship is strongly present in 5 of the 6 towns: NFD, STIL, HBG, AL, and HUCH. In IF, 1 tie missing = CLOSE.

RESULTS OF TESTING HYPOTHESIS II: From a KATZ AND KAHN perspective, the predicted relationship in MATRIX III is present in a weak form. The predicted relationship in MATRIX IV is strongly present.

\section{Parsonian}

HYPOTHESIS III: The greater the importance of an organization's output towards meeting a functional requirement of the organizational network, the more dominant the organization's position will be in the network. (Output) 
The organizational output to be considered is financial resources. This relationship would be shown to be present by the identification of the "Hangers On" pattern in both IMAGE MATRICES I and II.

\section{MATRICES I \& II}

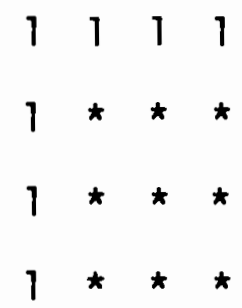

HYPOTHESIS III, based on the PARSONIAN typology, predicted relationships identifying the dominance of financial organizations. There is nothing as important to a community than money to finance programs and carry on business. The predicted relationship for MATRICES I and II are present in 3 towns - NFD, STIL, and HBG. These are strong relationships, exhibiting a high density of linkages and a definite "core-periphery" relationship between the "financial/information services" and the rest of the network.

In the other 3 towns - AL, HUCH, and IF - this relationship is not present in as strong and clear a form as in NFD, STIL, or HBG. In AL, the "core-periphery" pattern is present, but in a weaker form than in previous 3 towns.

MATRIX I: 2 ties missing = present but weak

MATRIX II: 4 ties missing: 1 = VERY CLOSE, $I=$ CLOSE, $I=$ present but weak, and $1=$ not present

In HUCH, BLOCK 2 is closer to the "core" position, as seen in the first 4 towns than BLOCK 1 . In this town, BUSINESS ORGANIZATIONS and FINANCIAL INSTITUTIONS are grouped together in BLOCK 2. The structure of 
the "financial dominance" inter-organization relational network may be different from the other communities for another reason, the presence of a major national corporation - 3M - in this community. Financial exchanges seem to center around the business "block," with the exception of the local government which sends and receives funds primarily within its own group (block 3 ).

In IF, BLOCK $I$ is made up of divisions of a major national corporation - The Boise Company. This block is central to MATRIX I, as far as "passing money." It is not central to MATRIX II as far as "receiving money." IF is a "company town"; therefore the company (Boise) directs funds within the community to pay for the needs and services supplied to workers. Funding for this company, however, comes from outside the community. When this is considered, BLOCK 2 (which contains the banks and the non-Boise businesses), becomes the "core" of a "core-periphery" organizational network.

RESULTS OF TESTING HYPOTHESIS III: From a PARSONIAN perspective, the predicted relationships in MATRICES I and II are strongly present in four of the six towns. Overall, this relationship is present in both MATRICES $I$ and II.

\section{FINDINGS}

After examination of the results of testing these hypotheses, it is appropriate to conclude that all of the three theoretically-base typologies that were tested - RESOURCE DEPENDENCE, KATZ AND KAHN, and PARSONIAN - are useful in describing the structure of the community networks examined in this study. This answers the first question put 
forth in this thesis. All three typologies - RESOURCE DEPENDENCE, focusing on inputs; KATZ AND KAHN - focusing on throughputs; and PARSONIAN - focusing on outputs - are relevant categorical tools for the community network data examined in this study. The next section of this thesis addresses the question, "Is organizational position (in a community network) most consistent with its input, throughput, or output processes?" 
CHAPTER 4

METHODOLOGY AND FINDINGS: COMPARISON OF TYPOLOGIES

In this section of this thesis: 1. a comparison of each theoretically-based partitioning with the data-driven partitioning in terms of the inclusiveness of organizational membership in each block will be made, and 2. a comparison will be made of each theoreticallybased partitioning with the data driven partitioning in terms of the "pureness" of the blocks in specific image matrices. The four "cell" structure of each theoretically-based typology will be assessed on the basis of "fit" with a four block model of community network structure, developed by the network analys is of empirical data on interorganizational relationships in six small towns in Minnesota. Next individual blocks of specific image matrices of partitioning schemes developed from each of the typologies will be compared on the bas is of block "pureness." The results of these two tests will answer the question that is central to this section of this thesis, "Is organizational position (in a community network) most consistent with its input, throughput, or output processes?" 


\section{VALIOITY}

This study involves three types of validity: face validity, criterion validity, and construct validity. Face validity refers to whether the instrument being used (in this study the different measures of position) adequately address and measure the concept being studied (in this research: position in a community network). Criterion validity involves multiple measurement of the same concept with more than one instrument. Construct validity relates the multiple measurement of the same concept to another specific theoretical concept (in this study: the three theoretical perspectives). The criterion variable used to determine the construct validity of these typologies is how well each predicts the position of specific organizations in community networks.

\section{TEST OF INCLUSIVENESS OF BLOCK MEMBERSHIP}

To facilitate comparison and interpretation, each theoreticallybased typology has a four block structure, and a four block block modeling solution was developed from the analysis of the empirical data. To standardize the order of hierarchical positioning of the blocks in image matrices associated with each theoretically-based typology as well as the data-driven partitioning, a set of decision rules were developed. (See APPENDIX a for a discussion of these decision rules.) Table V, VI, VII, VIII: four partitioning schemes.

TABLE IX shows the specific organizations that make up each of the individual blocks, in each of the six communities examined in this study, 
TABLE IX

DATA DRIVEN PARTITIONING

\begin{tabular}{|c|c|c|c|}
\hline CELL\# & NFD & STIL & $H B G$ \\
\hline I & $\begin{array}{l}4 \text { Banks } \\
1 \text { Education }\end{array}$ & $\begin{array}{l}3 \text { Banks } \\
1 \text { Newspaper } \\
1 \text { United Way }\end{array}$ & $\begin{array}{l}4 \text { Banks } \\
1 \text { Newspaper }\end{array}$ \\
\hline II & $\begin{array}{l}6 \text { Businesses } \\
3 \text { Associations }\end{array}$ & $\begin{array}{l}10 \text { Businesses } \\
1 \text { Health }\end{array}$ & 10 Businesses \\
\hline II I & $\begin{array}{l}2 \text { Education } \\
2 \text { Government } \\
2 \text { Churches } \\
1 \text { Socl Service } \\
1 \text { Newspaper }\end{array}$ & $\begin{array}{l}1 \text { Education } \\
3 \text { Government } \\
2 \text { Churches } \\
6 \text { Soc. Service } \\
1 \text { Heaith }\end{array}$ & $\begin{array}{l}2 \text { Education } \\
2 \text { Government } \\
6 \text { Soc. Service } \\
3 \text { Heaith }\end{array}$ \\
\hline IV & $\begin{array}{l}3 \text { Health } \\
7 \text { Soc. Service }\end{array}$ & $\begin{array}{ll}1 & \text { Health } \\
1 & \text { Foundation } \\
3 & \text { Associations } \\
1 \text { Chamber }\end{array}$ & $\begin{array}{l}1 \text { Health } \\
1 \text { United Way } \\
3 \text { Associations } \\
1 \text { Chamber } \\
2 \text { Churches }\end{array}$ \\
\hline
\end{tabular}


TABLE IX

DATA DRIVEN PARTITIONING

(continued)

\begin{tabular}{|c|c|c|c|}
\hline CELL\# & $\mathrm{AL}$ & $\mathrm{HUCH}$ & IF \\
\hline I & $\begin{array}{l}5 \text { Banks } \\
1 \text { Chamber }\end{array}$ & $\begin{array}{l}3 \text { Associations } \\
1 \text { Chamber } \\
1 \text { United Way } \\
2 \text { Churches } \\
1 \text { Government }\end{array}$ & $\begin{array}{l}3 \text { Businesses } \\
1 \text { Soc. Service }\end{array}$ \\
\hline II & $\begin{array}{l}7 \text { Businesses } \\
3 \text { Associations }\end{array}$ & $\begin{array}{l}8 \text { Businesses } \\
3 \text { Banks } \\
1 \text { Newspaper }\end{array}$ & $\begin{array}{l}4 \text { Businesses } \\
3 \text { Banks } \\
1 \text { Newspaper } \\
1 \text { Chamber }\end{array}$ \\
\hline III & $\begin{array}{l}3 \text { Government } \\
4 \text { Soc. Service } \\
1 \text { Heaith }\end{array}$ & $\begin{array}{l}1 \text { Government } \\
2 \text { Soc. Service } \\
4 \text { Heaith }\end{array}$ & $\begin{array}{l}2 \text { Government } \\
1 \text { Soc. Service } \\
3 \text { Associations } \\
2 \text { Churches } \\
1 \text { Union }\end{array}$ \\
\hline IV & $\begin{array}{l}1 \text { Soc. Service } \\
1 \text { Education } \\
4 \text { Health } \\
1 \text { United Way } \\
2 \text { Churches } \\
1 \text { Newspaper }\end{array}$ & $\begin{array}{l}5 \text { Soc. Service } \\
1 \text { Education }\end{array}$ & $\begin{array}{l}6 \text { Soc.Service } \\
2 \text { Education } \\
4 \text { Health } \\
2 \text { Government }\end{array}$ \\
\hline
\end{tabular}


based on a DATA-DRIVEN partitioning. TABLE $X$ gives the same information for the same communities, based on a PARSONIAN partitioning; TABLE XI based on a KATZ AND KAHN partitioning; and TABLE XII based on a RESOURCE DEPENDENCE partitioning.

Pair Bonds

In this study, a PAIR BONDS score is employed as a measure of the inclusiveness of organizational block membership in partitioning schemes based upon specific theoretically-based typologies of complex organizations. (Morgan, 1987) PAIR BONDS is a technique using sorting by sets to capture perceptions of the structure in social networks. A Pair-Bonds score represents the difference between the number of paired relationships present in a given block (based on the data-driven partitioning) and the number of paired relationships present in the same block (based on each theoretically-based partitioning scheme). The LOWER the score, the closer the "fit."

\section{Table XIII: Pair-Bonds Scores}

TABLE XIII shows the PAIR BONDS score for each of the three theoretically-based typologies, for each of the six communities examined in this study. Different partitioning schemes generated lower PAIR BONDS scores in specific communities. In an attempt to generalize across all six communities, the mean values of each of the theoretical partitionings were compared using the STUDENT's t-test, which is designed to be used for small number samples when little additional information is available. 
TABLE $X$

PARSONIAN PARTITIONING

\begin{tabular}{|c|c|c|c|}
\hline CELL\# & NFD & STIL & HBG \\
\hline I & $\begin{array}{ll}4 & \text { Banks } \\
1 & \text { Newspaper }\end{array}$ & $\begin{array}{l}3 \text { Banks } \\
1 \text { Newspaper }\end{array}$ & $\begin{array}{l}4 \text { Banks } \\
1 \text { Newspaper }\end{array}$ \\
\hline I I & 6 Businesses & 10 Businesses & 10 Businesses \\
\hline II I & $\begin{array}{l}2 \text { Government } \\
3 \text { Associations } \\
1 \text { Chamber } \\
1 \text { Health } \\
4 \text { Soc. Service }\end{array}$ & $\begin{array}{l}3 \text { Government } \\
3 \text { Associations } \\
1 \text { Chamber } \\
2 \text { Health } \\
1 \text { Foundation }\end{array}$ & $\begin{array}{l}2 \text { Government } \\
3 \text { Associations } \\
1 \text { Chamber } \\
1 \text { Health } \\
2 \text { Soc. Service }\end{array}$ \\
\hline
\end{tabular}

IV 4 Soc. Service

3 Education

2 Health

2 Churches
6 Soc. Service

1 Education

1 Health

2 Churches

1 United Way
4 Soc. Service

2 Education

3 Health

2 Churches

1 United Way

\begin{tabular}{|c|c|c|c|}
\hline CELL\# & NFD & STIL & HBG \\
\hline I & $\begin{array}{ll}5 & \text { Banks } \\
1 & \text { Newspaper }\end{array}$ & $\begin{array}{l}3 \text { Banks } \\
1 \text { Newspaper }\end{array}$ & $\begin{array}{l}3 \text { Banks } \\
1 \text { Newspaper }\end{array}$ \\
\hline II & 7 Businesses & 8 Businesses & 7 Businesses \\
\hline III & $\begin{array}{l}3 \text { Government } \\
3 \text { Associations } \\
1 \text { Chamber } \\
2 \text { Health } \\
1 \text { Soc. Service }\end{array}$ & $\begin{array}{l}2 \text { Government } \\
3 \text { Associations } \\
1 \text { Chamber } \\
1 \text { Health } \\
1 \text { Soc. Service }\end{array}$ & $\begin{array}{ll}3 & \text { Government } \\
3 & \text { Associations } \\
1 & \text { Chamber } \\
2 & \text { Health } \\
4 & \text { Soc. Service } \\
1 & \text { Union }\end{array}$ \\
\hline
\end{tabular}

4 Soc. Service

1 Education

3 Health

2 Churches

1 United Way
6 Soc. Service

1 Education

3 Health

2 Churches

1 United Way
4 Soc. Service

2 Education

2 Health

2 Churches 
TABLE XI

KATZ AND KAHN PARTITIONING

\begin{tabular}{llll} 
CELL\# & NFD & STIL & \multicolumn{1}{c}{ HBG } \\
\hline \multirow{2}{*}{ I } & $\begin{array}{l}3 \text { Associations } \\
\text { I Chamber }\end{array}$ & $\begin{array}{l}3 \text { Associations } \\
\text { 1 Chamber }\end{array}$ & $\begin{array}{l}3 \text { Associations } \\
\text { 1 Chamber }\end{array}$ \\
& & I United Way & $\begin{array}{l}1 \text { United Way } \\
1 \text { Education }\end{array}$
\end{tabular}

\begin{tabular}{llll}
\hline II & 6 Businesses & 10 Businesses & 10 Businesses \\
& 4 Banks & 3 Banks & 4 Banks \\
1 Newspaper & 1 Newspaper & 1 Newspaper \\
2 Education & &
\end{tabular}

$\begin{array}{lll}\text { III } \quad 2 \text { Government } & 3 \text { Government } & 2 \text { Government } \\ & 3 \text { Soc. Service } & \end{array}$

IV 5 Soc. Service 6 Soc. Service

1 Education 1 Education

3 Health

3 Health

2 Churches

2 Churches

1 Foundation

5 Soc. Service

1 Education

4 Health

2 Churches

\begin{tabular}{llll} 
CELL\# & AL & HUCH & IF \\
\hline \multirow{2}{*}{ I } & 3 Associations & 3 Associations & 3 Associations \\
& 1 Chamber & 1 Chamber & 1 Chamber \\
& 1 United Way & 1 United Way & 1 Education
\end{tabular}

\begin{tabular}{|c|c|c|c|}
\hline II & $\begin{array}{l}7 \text { Businesses } \\
5 \text { Banks } \\
1 \text { Newspaper }\end{array}$ & $\begin{array}{l}8 \text { Businesses } \\
3 \text { Banks } \\
1 \text { Newspaper }\end{array}$ & $\begin{array}{l}7 \text { Businesses } \\
3 \text { Banks } \\
1 \text { Newspaper }\end{array}$ \\
\hline II I & 3 Government & 2 Government & $\begin{array}{l}3 \text { Government } \\
3 \text { Soc. Service } \\
1 \text { Union }\end{array}$ \\
\hline IV & $\begin{array}{l}5 \text { Soc. Service } \\
1 \text { Education } \\
5 \text { Health } \\
2 \text { Churches }\end{array}$ & $\begin{array}{l}7 \text { Soc. Service } \\
1 \text { Education } \\
4 \text { Health } \\
2 \text { Churches }\end{array}$ & $\begin{array}{l}5 \text { Soc. Service } \\
1 \text { Education } \\
4 \text { Health } \\
2 \text { Churches }\end{array}$ \\
\hline
\end{tabular}


TABLE XII

RESOURCE DEPENDENCE PARTITIONING

\begin{tabular}{|c|c|c|c|}
\hline CELL\# & NFD & STIL & $H B G$ \\
\hline I & $\begin{array}{l}4 \text { Banks } \\
1 \text { Newspaper }\end{array}$ & $\begin{array}{l}3 \text { Banks } \\
1 \text { Newspaper }\end{array}$ & $\begin{array}{l}4 \text { Banks } \\
1 \text { Newspaper }\end{array}$ \\
\hline II & 6 Businesses & 10 Businesses & 10 Businesses \\
\hline I I I & $\begin{array}{l}2 \text { Government } \\
3 \text { Associations } \\
1 \text { Chamber }\end{array}$ & $\begin{array}{l}3 \text { Government } \\
3 \text { Associations } \\
1 \text { Chamber } \\
1 \text { United Way }\end{array}$ & $\begin{array}{l}2 \text { Government } \\
3 \text { Associations } \\
1 \text { Chamber } \\
1 \text { United Way }\end{array}$ \\
\hline IV & $\begin{array}{l}8 \text { Soc. Service } \\
3 \text { Education } \\
3 \text { Health } \\
2 \text { Churches }\end{array}$ & $\begin{array}{l}6 \text { Soc. Service } \\
1 \text { Education } \\
3 \text { Health } \\
2 \text { Churches } \\
1 \text { Foundation }\end{array}$ & $\begin{array}{l}6 \text { Soc. Service } \\
2 \text { Education } \\
4 \text { Health } \\
2 \text { Churches }\end{array}$ \\
\hline
\end{tabular}

\begin{tabular}{|c|c|c|c|}
\hline CELL\# & $A L$ & $\mathrm{HUCH}$ & If \\
\hline I & $\begin{array}{ll}5 & \text { Banks } \\
1 & \text { Newspaper }\end{array}$ & $\begin{array}{ll}3 & \text { Banks } \\
1 & \text { Newspaper }\end{array}$ & $\begin{array}{l}3 \text { Banks } \\
1 \text { Newspaper } \\
1 \text { Telephone Co }\end{array}$ \\
\hline II & 7 Businesses & 8 Businesses & 6 Businesses \\
\hline III & $\begin{array}{l}3 \text { Government } \\
3 \text { Associations } \\
1 \text { Chamber } \\
1 \text { United Way }\end{array}$ & $\begin{array}{l}2 \text { Government } \\
3 \text { Associations } \\
1 \text { Chamber } \\
1 \text { United Way }\end{array}$ & $\begin{array}{l}3 \text { Government } \\
3 \text { Associations } \\
1 \text { Chamber } \\
1 \text { Union }\end{array}$ \\
\hline
\end{tabular}

IV 5 Soc. Service 7 Soc: Service

1 Education

5 Health

1 Education

2 Churches

4 Health

2 Churches

8 Soc. Service

2 Education

4 Health

2 Churches 
TABLE XIII

PAIR BONDS MEASURE OF DISTANCE BETWEEN DATA-DRIVEN PARTITIONING AND THREE THEORETICALLY-BASED PARTITIONINGS

\begin{tabular}{lccccccc} 
PARTITIONING & NFD & STIL & HBG & AL & HUCH & IF & MEAN \\
\hline PARSONIAN & 156 & 91 & 98 & 138 & 143 & 210 & 139.3
\end{tabular}

\begin{tabular}{llllllll}
\hline KATZ \& KAHN & 152 & 113 & 140 & 142 & 90 & 172 & 134.8
\end{tabular}

RESOURCE

DEPENDENCE

$122 \quad 103$

$85 \quad 139 \quad 116 \quad 198$

127.2

TABLE XIV: T-TEST TABLE

TABLE XIV shows the result of the comparisons of mean values of PAIR BONDS scores for each pair of partitioning schemes, developed from the three theoretically-based typologies examined in this study.

Results of Pair Bonds Test

FIRST, after comparing the mean values of PAIR BONDS scores for each pair of partitioning schemes, it is not possible to say that there is any all three partitionings scored the same. This shows that different theoretically-based typologies develop partitioning schemes that best "fit" the network structure of different communities examined in this study. 


\section{TABLE XIV}

\section{STUDENT'S $\mathrm{t}$-TEST VALUES}

TEST I: COMPARISION OF PARSONIAN AND KATZ \& KAHN MEAN PAIR BONDS VALUES

$$
\text { NULL: } \bar{X}_{P}=\bar{X}_{K \& K}
$$

$$
\begin{aligned}
& \text { ALTERnATIVE: } \overline{x_{P}}=/=\overline{X_{\text {K\&K }}} \\
& t_{\text {expected }}=6.314 \\
& t_{\text {observed }}=0.2117
\end{aligned}
$$

CANNOT REJECT NULL HYPOTHESIS

TEST II: COMPARISON OF PARSONIAN AND RESOURCE DEPENDENCE MEAN PAIR BONDS VALUES

$$
\text { NULL: } \bar{X}_{P}=\overline{X_{R D}}
$$

$$
\begin{aligned}
& \text { ALTERnATIVE: } \bar{X}_{P}=/=\bar{X}_{R D} \\
& t_{\text {expected }}=6.314 \\
& t_{\text {observed }}=0.4960
\end{aligned}
$$




\section{TABLE XIV}

\section{STUDENT'S $\mathrm{t}$-TEST VALUES}

(continued)

TEST III: COMPARISON OF KATZ \& KAHN AND RESOURCE DEPENDENCE MEAN PAIR BONDS VALUES

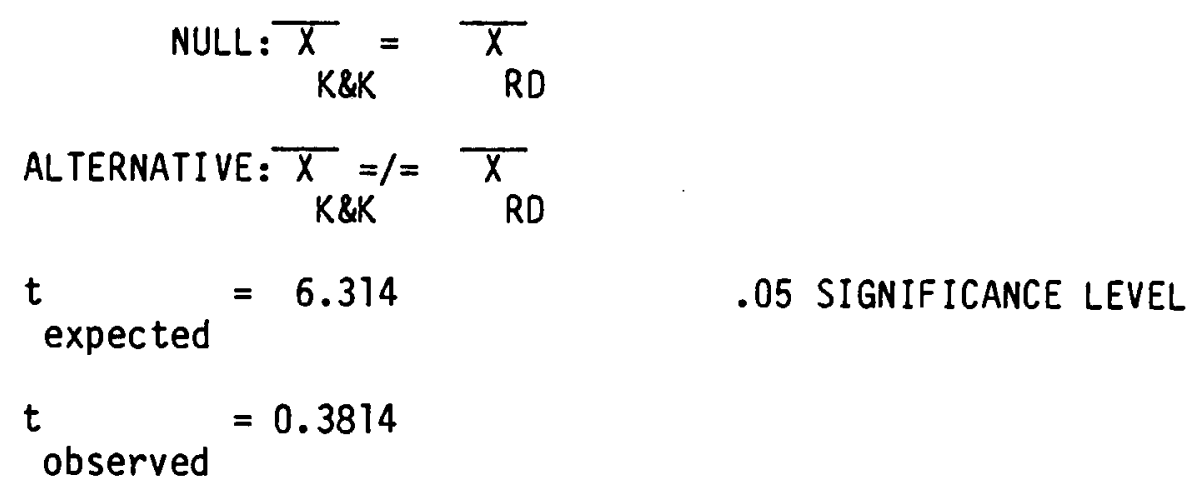

CANNOT REJECT NULL HYPOTHESIS

TEST OF BLOCK PURENESS

As discussed in Chapter III, various criteria have been developed for assessing the "fit" or validity of specific blockmodels. "Fat" fit requires an identity of the ties between the blocks, on one hand; and the ties between the nodes that are mapped into them, on the other. (Carrington et al., 1979:221) "Lean" fit requires only that elements (nodes) have 0-valued ties wherever the blocks into which they are mapped have 0-valued ties. An "alpha"-fit requires that an "alpha" value, between 0 and 1 , be specified; and that there be 1 's on the image statistically-significant differences between the populations (partitionings of organizations) that these three typologies were based upon. 
SECOND, different partitioning schemes generated lower PAIR BONDS scores in specific communities. The lower the PAIR BONDS score, the more similar groupings of organizations are when a theoretically-based partitioning is compared to a data-driven one. The RESOURCE DEPENDENCE partitioning scored lowest in NFD and HBG. The KATZ AND KAHN partitioning in IF and HUCH. The PARSONIAN partitioning in STIL. In AL matrices wherever blocks in the data matrices have a density of I's greater than "alpha", and 0's elsewhere in the data matrices. (Arabie et al., 1978:32) An "alpha" fit criterion in employed in this study. The "alpha" value is the average density of ties in a specific image matrix.

\section{"b" Statistic}

The Carrington, Heil and Berkowitz "b" statistic is a measure of how "pure" the composition of individual blocks are in a particular partitioning. The average density of ties in a matrix (alpha) supplies the base-line value. Ex. alpha=.121. A "worse fit" partitioning would have all "l" blocks with a density of .122 and all "0" blocks with a density of .120 . The "b" value for a matrix with this block structure would be $.00 x$, close to zero. A partitioning which would approach "best-fit" would have "l" blocks with a density close to 1.00 and "0" block with a density close to 0.000 . When the "b" statistic is used, the HIGHER the score, the "purer" the block composition.

It is important to note that in this study specific relationships are being analyzed via the process of examining individual image matrices. The purpose of this "test" is to see how "pure" a division each theoretical partitioning makes between the "blocks" of organizations 
engaged in specific relationships. What follows is a brief review of the content of the relationships described by each individual image matrix.

The seven different inter-organizational relations examined in this thesis, and the image matrix number that corresponds to each relationship are:

IMAGE MATRIX 1. "Pass funds to" (transaction relation)

IMAGE MATRIX 2. "Receive funds from" (transaction relation)

IMAGE MATRIX 3. "Assign personnel to cooperate on economic developments" (boundary penetration relation)

IMAGE MATRIX 4. "Assign personnel to cooperate on human services planning" (boundary penetration relation)

IMAGE MATRIX 5. "Have letters of agreement/contracts with" (instrumental relation)

IMAGE MATRIX 6. "Their evaluation is critical to your organization's self-image" (sentiment relation)

IMAGE MATRIX 7. "Send personnel to for services and products" (instrumental relation)

TABLE XV: "b" STATISTIC VALUES

SEE APPENDIX B FOR TABLES XVII - XXIII: "b" statistic values for each image matrix, in each community, for each partitioning scheme.

TABLE XI presents an across-town summary of the Carrington, Heil, and Berkowitz "b" statistic on an image matrix-by-image matrix basis, for the individual partitioning schemes developed from each specific theoretically-based typology. 
TABLE XV

AN ACROSS-COMMUNITY COMPARISON OF "b" STATISTIC VALUES

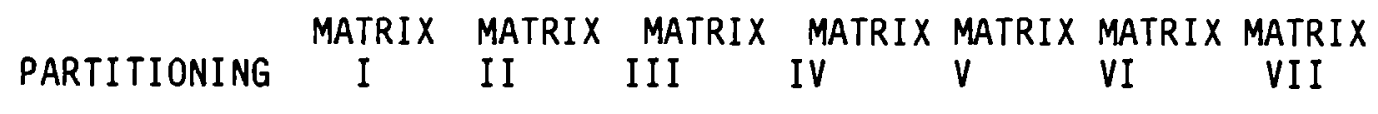

\begin{tabular}{llllllll}
\hline & $\mathrm{a} .2$ & $\mathrm{a} .3$ & $\mathrm{a} .5$ & $\mathrm{a} .2$ & $\mathrm{a} .1$ & $\mathrm{a} .2$ & $\mathrm{a} .3$ \\
PARSONIAN & $\mathrm{b} .4$ & $\mathrm{~b} .3$ & $\mathrm{~b} .1$ & $\mathrm{~b} .3$ & $\mathrm{~b} .5$ & $\mathrm{~b} .3$ & $\mathrm{~b} .1$ \\
& $\mathrm{c.0}$ & $\mathrm{c} .0$ & $\mathrm{c} .0$ & $\mathrm{c.1}$ & $\mathrm{c.0}$ & $\mathrm{c.1}$ & $\mathrm{c.2}$ \\
& & & & & & &
\end{tabular}

$\begin{array}{llllllll} & \text { a.0 } & \text { a.2 } & \text { a.4 } & \text { a.1 } & \text { a.3 } & \text { a.3 } & \text { a.2 } \\ \text { KATZ \& KAHN } & \text { b.5 } & \text { b.4 } & \text { b.1 } & \text { b.5 } & \text { b.3 } & \text { b.2 } & \text { b.4 } \\ & c .1 & \text { c.0 } & \text { c.1 } & \text { c.0 } & \text { c.0 } & \text { c.1 } & \text { c.0 }\end{array}$

\begin{tabular}{llllllll} 
RESOURCE & $\mathrm{a} .3$ & $\mathrm{a} .3$ & $\mathrm{a} .6$ & $\mathrm{a} .1$ & $\mathrm{a} .2$ & $\mathrm{a} .3$ & $\mathrm{a} .3$ \\
DEPENDENCE & $\mathrm{b} .2$ & $\mathrm{~b} .2$ & $\mathrm{~b} .0$ & $\mathrm{~b} .4$ & $\mathrm{~b} .3$ & $\mathrm{~b} .1$ & $\mathrm{~b} .2$ \\
& $\mathrm{c.1}$ & $\mathrm{c} .1$ & $\mathrm{c.0}$ & $\mathrm{c.1}$ & $\mathrm{c.1}$ & $\mathrm{c.2}$ & $\mathrm{c.1}$ \\
\hline
\end{tabular}

For each community studied:

KEY

$a .=$ "b" statistic value for theoretical partitioning is greater than data-driven partitioning "b" statistic value.

b. = "b" statistic value for theoretical partitioning is equal to data-driven partitioning "b" statistic value.

$c$. = "b" statistic value for theoretical partitioning is less than data-driven partitioniong "b" statistic value.

Results of "b" Statistic Test

Each partitioning scheme, developed from one of the three theoretically-based typologies, "fits" better with specific relationships and their accompanying image matrices. The PARSONIAN partitioning "fits" best for IMAGE MATRIX IV (cooperate on human service planning), IMAGE 
MATRIX VII(send personnel to for services and products); and "fits" second best for IMAGE MATRICES II, and III. The KATZ AND KAHN partitioning " $f i t s "$ best for IMAGE MATRIX $v$ (have contracts with), and "fits" 2nd best form IMAGE MATRICES III, and VI. The RESOURCE DEPENDENCE partitioning "fits" best for IMAGE MATRIX I (send money to), IMAGE MATRIX II(receives money from), IMAGE MATRIX III (cooperate on economic planning), and IMAGE MATRIX VI (their evaluation is critical to your organization's self-image); and "fits" second best for IMAGE MATRICES IV, V, VII.

After the examination of an across-town summary of the Carrington, Heil, and Berkowitz "b" statistic, on an image matrix-by-image matrix basis, for the individual partitioning schemes developed from the RESOURCE DEPENDENCE, the KATZ AND KAHN, and the PARSONIAN theoreticallybased typologies; it is not possible to say that any one partitioning scheme is consistently superior to any of the others. While different theoretically-based typologies seem to develop partitioning schemes that are more appropriate for different specific relationships, RESOURCE DEPENDENCE is the only theoretically-based typology that yields a partitioning that is best or second best for all seven relationships. However, since there is not an absolute standard to measure these scores against, the rating of any theoretically-based typology as "best" or "2nd best," in terms of a given relationship, cannot be considered statistically significant. As with the PAIR-BONDS scores, no one partitioning scheme, developed from one of the three theoretically-based typologies, is consistently superior to any of the others. 


\section{FINDINGS}

After conducting 1) the test of inclusiveness of block membership using Pair Bonds scores, and 2) the test of block "pureness" utilizing the Carrington, Heil, and Berkowitz "b" statistic, no one theoreticallybased typology - RESOURCE DEPENDENCE, KATZ AND KAHN, or PARSONIAN - has been shown to be consistently superior to the others based on how well each predicted the position of specific organizations in community networks. The central question of this section of this thesis, "Is organizational position (in a community network) most consistent with its input, throughput, or output processes?", cannot be answered in any kind of a statistically-significant, conclusive manner based on the data examined in this study. 


\section{CHAPTER VI}

\section{CONCLUSIONS}

This thesis was designed to test the "fit" of three standard typologies of complex organizations at the community level. The three typologies were originally developed from data on internal organizational characteristics. This thesis examines these typologies using network data from six Minnesota towns. This thesis tested three hypotheses which predicted specific inter-organizational relationships that should be present in the empirical data. A typology was considered relevant for use in this study, if the inter-organizational relationship, predicted by the corresponding hypothesis, was found to be present in the empirical data. The findings showed that all three typologies examined are relevant categorical tools for the network data employed in this study.

Organizations can be thought of as attempting to "position" themselves in their operating environments in such a fashion as to enable themselves to best address their operating problems. However, organizations face not one, but three different problems, relating to: 1 . inputs, 2. throughputs, and 3. outputs. In "global"terms," it is only possible for any particular organization to occupy a single position in its environment. The second section of this thesis examines whether organizational position is most consistent with its input, throughput, or output processes. Tests of the degree of inclusiveness of block membership, and of block "pureness," show it is not possible to 
conclusively determine whether organizational position in a community network is most consistent with its input, throughput, or output processes.

One possible explanation may be that the tests employed are not valid for the study being conducted. This does not appear to be so, as both measures have been utilized in previously published research (Carrington et a1., 1979; Morgan, 1987) A second possible explanation is suggested when the results of the hypothesis testing of this thesis, are considered in the context of the writings on community network structure.

\section{REVIEW OF HYPOTHESES IN CONTEXT DF COMMUNITY NETWORK}

HYPOTHESIS I: The greater the dependence on external-to-the-organization sources of funding by the members of an organizational network, the more dominant the positions of financial-resources controlling organizations. (INPUTS: RESOURCE DEPENDENCE)

Organizations will respond to an interest group to the extent that it has direct control over resources needed by the organizations. HYPOTHESIS I was found to be supported; the predicted relationship was found to be strongly present in the empirical data. From the examination of this data, it appears that "financial dominance/influence" is one dimension of inter-organizational networks in communities. It should be noted that specific characteristics of communities, most notably the presence of large, national corporations which are based outside of the local area, can generate variance in the basic "core-periphery" dominance pattern. 
This is consistent with research done by Beth Mintz and Michael Schwartz (1985). These authors put forth the "Theory of Financial Hegemony" which describes intercorporate power in terms of the dominance of financial institutions in the corporate interlock network. Financial hegemony is a form of structural hegemony, and operates when the actions of one social institution (a coordinated group of organizations tied to a specific functional area: in this study a "block") determine the viable options available to other institutions. Mintz and Schwartz state that if such constraint occurs regularly in a social system, the dominant structure exercises a noninterventionist leadership that allows for coordination of the other social "units" (institutions/organizations/ blocks) without either overt coercion or systematic ideological manipulation (1985:xii).

HYPOTHESIS II: The greater the similarity between organizational throughputs, the greater the probability of inter-organizational cooperation. (THROUGHPUT: KATZ AND KAHN)

Organizations that process the same throughput will be more likely to engage in cooperative projects involving the pooling of personnel to address problems of concern to both organizations.

Two different types of cooperation are addressed in the empirical data: CONTINGENT COOPERATION, and MANDATED COOPERATION (Laumann et al., 1978). CONTINGENT COOPERATION OCCurs when organizations balance their commitments to welfare of the "community" with their own more specialized goals. For example Galaskiewicz observes that "...manufacturers, retailers, and financial institutions perform important economic functions. Thus they have a need to control the distribution of money in 
an interorganizational system." (1979:65) HYPOTHESIS II, in this form, is not conclusively supported; the predicted relationship is present but in a weak form in the empirical data. (See Image Matrix III)

The second type of cooperation is concerned with cooperation on human services planning. HYPOTHESIS II, in this form, is supported; the predicted relationship is strongly present in the empirical data. (See Image Matrix IV). This is an example of MANDATED COOPERATION (Laumann et al., 1978) which usually involves a centralized control agency (i.e., local government) which of ten controls funding, and has the power to structure or restructure the entire network.

The result is consistent with recent work on social service organizations. Government programs directly affect planning of public and voluntary organizations at both local and state levels. (Rothman, 1974; Schottland, 1963) Influence is accorded in direct proportion to the ability to control the resources necessary for organizational survival. Money provides funders with a critical source of power to command agency decision making. (Brager \& Holloway, 1978) These authors go on to note that the vast expansion of government funding of social services, on all levels, realigned power in both the public and private sectors. Mutual dependence (i.e., a cooperative relationship) often develops between the agency and its funder. (Brager \& Holloway, 1978:46)

In this thesis the relationship between government and social services was emphasized in two ways. First, the communities selected to be studied were outside of the orbit of metropolitan areas. This is so as not to have the towns be unduly influenced by proximally offered services from other municipalities. Second, all state and federal 
agencies were removed from the original data before any network analysis was started. Both of these controls are designed to focus the attention of this study to the relationship between local government and social service organizations.

HYPOTHESIS III: The greater the importance of an organization's output towards meeting a functional requirement of the organizational network, the more dominant the organization's position will be in the network. (OUTPUTS: PARSONIAN)

The element of an inter-organizational network that addresses a specific functional requirement of that network, should occupy a dominant position in any relationships directly pertaining to addressing that particular need. The output that was considered in this hypothesis test was financial resources.

As in the discussion of HYPOTHESIS I, this is consistent with research done by Beth Mintz and Michael Schwartz (1985). The "Theory of Financial Hegemony" also can be used to explain the dominance of financial institutions from a Parsonian perspective. Financial hegemony is one form of structural hegemony. When the actions of one social institution (a coordinated group of organizations tied to a specific functional area: in this study a "block") determine the viable options available to other institutions, this is an example of structural hegemony. Mintz and Schwartz state that if such constraint occurs regularly in a social system, the dominant structure exercises a noninterventionist leadership that allows for coordination of the other social "units" without either overt coercion or systematic ideological manipulation (1985:xii) 
Based on this study, two dimensions of community network structure are identified: "FINANCIAL DOMINANCE" (by both RESOURCE DEPENDENCE and PARSONIAN), and "COOPERATION" (by KATZ AND KAHN). It should be noted that the "COOPERATION" identified by KATZ AND KAHN is what has been labeled "MANDATED COOPERATION", and only concerns "human services planning." These findings are consistent with research done by Hunter (1953:62) on community power structure in "Regional City": "...I doubt seriously that power forms a single pyramid with any nicety in a community the size of Regional City. There are pyramids of power in this community which seem more important to this discussion than a single pyramid." Hunter points out that while Coca-Cola is the dominant industry in "Regional City" (Atlanta) the President of Coca-Cola is "at the top" of only one of the pyramids of power in the community. He does not have the same influence in other areas where "old money," "influence," and "social service to the community" are criterions. Galaskiewicz (1979) also identifies a variety of "interorganizational resource networks" in a given community. These resource networks could be thought of as "dimensions," corresponding to a linkage or set of linkages all concerned with a particular category of network relation.

The fact that a community network is a multidimensional network also explains why no one theoretically-based typology was consistently superior to the others. The two dimensions identified in this research-financial dominance and mandated cooperation--are necessary but not sufficient for the description of a community network.

Also, the communities examined in this study vary along these multiple dimensions. This would result in different typologies best 
"fitting" or "describing" the structure of that specific community network, with no one typology best "fitting" all the community networks examined. This is exactly what occurred in this thesis.

No claim is made that these are the only, or even the most important dimensions of community network structure. The choice of relationships examined in this thesis may be responsible for why Hypothesis I and Hypothesis III turn out to be the same. The part of this data set used in this thesis contained specific information on financial exchanges that was not available in regard to other significant dimensions, such as political power or influence. Still, no single theoretically-based typology tested in this study identified both of the dimensions identified in this study. These findings argue for a synthesis of the theoretical perspectives involved, as opposed to pragmatic posturing and the contention that any single typology of complex organizations is "right" in and of itself.

\section{SUMMARY}

In the THESIS PROPOSAL document which was the basis for this study, it was proposed that "This thesis will constitute an attempt to reconcile newer forms of contextual or relational data with typologies which were originally developed from internal organizational sources." This was the focus of the first section of this study. All three typologies tested were found to be relevant categorical tools for grouping the empirical, community network data. In the second section of this thesis, an attempt was made to determine if any one typology best "fit" the empirical data. Tests of the degree of inclusiveness of block membership, and of block 
"pureness," show it is not possible to conclusively determine whether organizational position in a community network is most consistent with its input, throughput, or output processes. However two dimensions of community network structure are identified in this study, "FINANCIAL DOMINANCE" and "MANDATED COOPERATION." Organizations that control financial resources occupy a dominant position in a community. What is also significant is that, even in regard to the delivery of social services, the organizations that control the funding - financial resources - are in a dominant position where the can force other organizations to cooperate on joint projects. From the data examined in this thesis, control of financial resources is the single most important factor in determining dominant position in a community network.

\section{SUGGESTIONS FOR FUTURE RESEARCH}

The process of conducting this thesis project has suggested several possible areas where future research may prove fruitful. First, more data sets need to be analyzed. Original studies need to be conducted, as opposed to the replication of previous work which characterized much of the earlier work in the area of block modeling analysis. This could address whether identified dimensions of community network structure are only locally-relevant; or whether these can be generalized to a larger population of communities.

Second, the linkage of the open system - type organizational theorists and community network analysts needs to be strengthened. The methodology employed in studies of community network structure would prove valuable to the organizational theorists; and the community network 
analysts could benefit from the previously collected data sets concerning complex organizations. Also, by focusing on the organization as a common unit of analysis, community network studies would become more "standardized". More studies need to be pursued doing "complete" network analysis - i.e., community network analysis - with organizations as the unit of analysis. One interesting possible future study might compare populations of communities where the primary source of financial resources originate outside the community with populations of communities where the primary source of financial resources is internal to the community. Another comparison could involve differences in geographical location. Are community networks structured the same in the Eastern or Southwestern United States as they are in Minnesota? Finally, what effect does a differences in the central industry of a community have on its network structure? Future research could focus on differences in network structure between populations of agriculturally-oriented communities as opposed to manufacturing-oriented communities.

Third, and this is closely tied to the previous point, different "content" types of relationships need to be examined. In particular, relationships whose presence would reflect previously identified dimensions of community network structure. Examples of some of these different types of relationships would include legitimation, influence, and political power.

Finally, some methodological tool needs to be added to or integrated into the block modeling analysis process that will facilitate the weighing of the different dimensions identified in research studies. Snyder and Kick (1979) attempt to do exactly this by first block modeling 
world systems data, and then using regression analys is to establish weights for the different factors involved. 


\section{SELECTED BIBLIOGRAPHY}

Aldrich, H.E., \& Pfeffer, J. 1976. "Environments of Organizations," Annual Review of Sociology, Vol. 2.

Aldrich, H.E. 1979. Organizations and Environments, Prentice-Hall, Inc: Englewood Cliffs, N.J.

Arabie, P., \& Boorman, S.A. 1982. "Blockmodels: Developments and

Prospects," in Classifying Social Data. H.C. Hudson (Ed.), Jossey-Bass: San Francisco, Ca.

Arabie, P., Boorman, S.A., L Levitt, P.R. 1978. "Constructing Blockmodels: How and Why," Journal of Mathematical Psychology, 17, 1, pp. 21-63.

Baird, L.S., Hamer, W.C. 1979. "Individual Versus System Rewards: Who's Dissatisfied, Why, and What is Their Likely Response?" American Management Journal, 22, 4, pp. 783-792.

Barnes, J.A. 1969. "Networks and Political Process," in Mitche11, J.C. (Ed.) 1969. Social Networks in Urban Situations, Manchester University Press: Manchester, England.

Benson, J.K. 1975. "The Interlocking Network as a Political Economy." Administrative Sciences Quarterly, 20, 2, pp. 229-249.

Berkowitz, S.0. 1982. An Introduction to Structural Analysis: The Network Approach to Social Research, Butterworths: Toronto, Canada.

Bertalanffy, L. von 1968. General Systems Theory: Foundations, Development, Application, in Rapoport, A. 1986. General Systems Theory, Abacus Press: Cambridge, Mass.

Bidwell, C.E., \& Kasarda, J.D. 1985. The Organization and Its Ecosystem: A Theory of Structuring In Organizations, JAI Press, Inc.: Greenwich, Conn.

Blau, P.M., \& Scott, W.R. 1962. Formal Organizations, Chandler Publishing: San Francisco, Ca.

Brager. G., \& Holloway, S. 1978. Changing Human Service Organizations, The Free Press: New York. 
Breiger, R.L., Boorman, S.A., \& Arabie, P. 1975. "An Algorithm for Clustering Relational Data with Applications to Social Network Analysis and Comparison with Multidimensional Scaling, "Journal of Mathematical Psychology, 12, 1, pp. 328-383.

Burt, R.S. 1978. "Cohesion versus Structural Equivalence as a Basis for Network Subgroups," in Knoke, D. and Kuklinski, J.H. 1982. Network Analysis, Sage Publishing: Beverly Hills, Ca.

Carrington, P.J., Heil, G.H., \& Berkowitz, S.D. 1979. "A Goodness-of-Fit Index for Blockmodels." Social Networks, 2, pp. 219-234.

Clark, T.N. 1968. Community Structure and Decision-making: Comparative Analysis, Chandler Publishing Co.: San Francisco, Ca.

DiMaggio, P., \& Powell, W.W. 1983. "The Iron Cage Revisited: Institutional Isomorphism and Collective Rationality in Organizational Fields," American Sociological Review, 48, pp. 147-160.

Drucker, P.F. 1986. The Frontiers of Management: Where Tomorrow's Decisions are Being Shaped Today, Truman Talley Books: New York.

Durkheim, E. 1938. The Rules of the Sociological Method, Translated by Catlin, G.E.G. The Free Press: New York.

Etzioni, A. 1961. A Comparative Analysis of Complex Organizations, Free Press of Glencoe: New York.

Evan, W. 1966. "The Organizational Set," in Thompson, J. (Ed.) 1966. Approaches to Organizational Design, University of Pittsburg Press: Pittsburg, Pa.

Freeman, J.H. 1978. "The Unit of Analysis in Organizational Research," in Meyer, M.W. \& Associates (Ed.) 1978. Environments and Organizations, pp. 335-351, Jossey-Bass: San Francisco, Ca.

Galaskiewicz, J. 1979. Exchange Networks and Community Politics, Sage Publishing: Beverly Hills, Ca.

Goffman, E. 1961. Asylums, Doubleday: Garden City, N.Y.

Gouldner, A.W. 1959. "Organizational Analysis," in Merton, R.K., Brown, L., \& Cottre11, L.S. (Ed.) 1959. Sociology Today, pp. 400-428, Basic Books: New York.

Ha11, R.H. 1972, 1987. Organizations: Structure and Process, Prentice-Hall, Inc.: Englewood Cliffs, N.J.

Hannan, M.T., \& Freeman, J. 1977. "The Population Ecology of Organizations," American Journal of Sociology, 82, 5, pp. 929-966. 
Hunter, F. 1953. Community Power Structure: A Study of Decision Makers, Doubleday \& Co.: Garden City, N.Y.

Hunter, F. 1980. Community Power Succession: Atlanta's Policy Makers Revisited, University of North Carolina Press: Chapel Hill, N.C.

Katz, D., \& Kahn, R. 1966, 1978. The Social Psychology of Organizations, 2nd Edition, John Wiley \& Sons: N.Y.

Katz, D., \& Kahn, R. 1971. "Open-System Theory," in Mauer, J. (Ed.) 1971. Readings in Organizational Theory: Open-System Approaches, Random House: New York, N.Y.

Knoke, D., \& Kuklinski, J.H. 1982. Network Analysis, Sage Publishing: Beverly Hills, Ca.

Kuhn, A., \& Beams, R. 1982. The Logic of Organization, Jossey-Bass Publishers: San Francisco, CA.

Laumman, E.0. 1973. Bonds of Pluralism: The Form and Substance of Urban Social Networks, John Wiley \& Sons: New York, N.Y.

Laumann, E.0., \& Pappi, F.U. 1976. Networks of Collective Action, Academic Press: New York, N.Y.

Laumann, E.0., Galaskiewicz, J., \& Marsden, P.V. 1978. "Community Structure As Interorganizational Linkages," American Journal of Sociology, 4, pp. 455-484.

Lazerfeld, P.F. 1972. "Some Remarks on Typological Procedures in Social Research," in Lazerfeld, P.F., Pasanella, A.K., \& Rosenberg, M. (Ed.) 1972. Continuities in the Language of Social Research, The Free Press: New York.

Levine, S., \& White, P. 1961. "Exchange as a Conceptual Framework for the Study of Interorganizational Relationships." Administrative Sciences Quarterly, 5, 1, pp. 583-610.

Light, J.H., \& Mullins, N.C. 1979. "A Primer on Blockmodeling Procedure," in The Center for Advanced Study in the Behavioral Sciences 1979. Perspectives on Social Network REsearch, Academic Press: New York.

Lincoln, J.R. 1982. "Intra-(\& Inter-)Organizational Networks," in Bacharach, S.B. (Ed.) 1982. Research in the Sociology of Organizations, JAI Press, Inc.: Greenwich, Conn.

Marsden, P.V., \& Lin, N. 1982. Social Structure and Network Analysis, Sage Publishing: Beverly Hills, Ca.

Mauer, J.G. (Ed.) 1971. Readings in Organizational Theory: Open System Approaches, Random House: New York, N.Y. 
McKelvey, B. 1982. Organizational Systematics, University of California Press: Berkeley, Ca.

Meyer, J.W., \& Rowan, B. 1977. "Institutionalized Organizations: Formal Structure as Myth and Ceremony," American Journal of Sociology, 83, pp. 340-363.

Mintz, B., \& Schwartz, M. 1985. The Power Structure of American Business, University of Chicago Press: Chicago, I11.

Mitche11, J.C. (Ed.). 1969. Social Networks in Urban Situations, University of Manchester Press: Manchester, England.

Morgan, D.L. 1987. "Rehabilitating A Techniques To Measure Perceived Social Networks." Social Networks, 9, pp. 135-152.

O'Brien, J., Whitelaw, N., \& Anderson, T.P. Spring 1980. "Characteristics of Senior Centers in Minnesota," A Report to the Minnesota Board on Aging.

O'Brien, J., Whitelaw, N., \& Anderson, T.P. Winter 1981. "Analysis of Six Minnesota Communities and Their Senior Centers," A Report to the Minnesota Board on Aging.

Parsons, T., \& Smelser, N.J. 1956. Economy and Society, The Free Press: New York.

Parsons, T. 1960. Structure and Process in Modern Societies, The Free Press: Glencoe, III.

Perrow, C. 1970. Organizational Analys is: A Sociological View, Wadsworth Publishing Company, Inc.: Belmont, Ca.

Perrow, C. 1986. Complex Organizations, Random House: New York, N.Y.

Pfeffer, J. 1978. Organizational Design, AHM Publishing Corporation: Arlington Heights, III.

Pfeffer, J., \& Salanick, G.R. 1978. The External Control of Organizations, Harper \& Row, PubTishers: New York, N.Y.

Pfeffer, J. 1982. Organizations and Organization Theory, Pitman Publishing, Marshfield, Mass.

Ramos, A.G. 1981. The New Science of Organizations, University of Toronto Press: Toronto, Canada.

Reynolds, P.D. 1971. A Primer in Theory Construction, The Bobbs-Merrill Company, Inc.: Indianapolis, Indiana. 
Rothman, J. 1974. "Three Models of Community Organization Practice: Their Mixing and Phasing" in Cox, F.M., Erlich, J.C., Rothman, J., \&

Tropman, J.E. (Ed.) 1979. Strategies of Community Organization, F.E. Peacock, Publishers, Inc.: Itasca, I11.

Salancik, G. L. 1979. "Interorganizational Dependence and Responsiveness to Affirmative Action: The Case of Women and Defense Contractors." Academy of Management Review, 7, 3, pp. 353-360.

Sanders, P. 1982. "Phenomenology: A New Way of Viewing Organizational Research." Academy of Management Review, 7, 3, pp. 353-360.

Schottland, M. 1963. "Funding Social Service Programs," in Titmus. R.M. 1974. Social Policy: An Introduction, Pantheon Books: New York.

Scott, W.R. 1981, 1987. Organizations: Rational, Natural, and Open Systems, Prentice-Ha1T, Inc.: Englewood Cliffs, N.J.

Snyder, D., \& Kick, E.L. 1979. "Structural Position in the World System and Economic Growth, 1955-1970: A Multiple-Network Analys is of Transactional Interaction," American Journal of Sociology, 84, pp. $1096-1126$

Terreberry, S. 1968. "The Evolution of Organizational Environments," American Sociological Quarterly, 12, pp. 590-613.

Titmus, R.M. 1974. Social Policy: An Introduction, Pantheon Books: New York.

Turk, H. 1970. "Interorganizational Networks in Urban Society: Initial Perspectives in Comparative Research." American Sociological Review, 35,1 , pp. $1-18$.

Warren, R. 1967. "The Interorganizational Field as a Focus for Investigation," American Sociological Quarterly, 12, pp. 396-419.

Weber, M. 1967. The Theory of Social and Economic Organization, Henderson, A.H., and Parsons, T. (Ed.), Free Press: GTencoe, I11.

Weick, K.E. 1976. "Educational Organizations as Loosely Coupled Systems," Administrative Sciences Quarterly, $21, \mathrm{pp} .1-19$.

White, H.C. 1974. "Null Probabilities for Blockmodels of Social Networks," Unpublished Paper, Department of Sociology, Harvard University.

White, H.C., Boorman, S.A., \& Breiger, R.L. 1976. "Social Structure from Multiple Networks I: Blockmodels of Roles and Positions," American Journal of Sociology, 81, 4, pp. 730-780. 
Yuchtman, E., \& Seashore, S.E. 1967. "A System Resource Approach to Organizational Effectiveness," American Sociological Review, 32, pp. $891-903$. 
APPENDIX A

DECISION RULES 
TABLE XVI

DECISION RULES

\begin{tabular}{|c|c|c|c|c|c|}
\hline CELL\# & $\begin{array}{l}\text { DECISION } \\
\text { RULE }\end{array}$ & PARSONS & KATZ \& KAHN & $\begin{array}{c}\text { RESOURCE } \\
\text { DEPENDENCE } \\
\end{array}$ & $\begin{array}{l}\text { DATA } \\
\text { DRIVEI }\end{array}$ \\
\hline I & $\begin{array}{l}\text { Financial } \\
\text { (Other) }\end{array}$ & $\begin{array}{c}\text { Goal } \\
\text { Attainment }\end{array}$ & Adaptive & $\begin{array}{l}\text { Money \& } \\
\text { Information }\end{array}$ & $\begin{array}{l}\text { NFD4 } \\
\text { STIL4 } \\
\text { HBG4 } \\
\text { AL4 } \\
\text { HUCH3 } \\
\text { IFI } \\
\end{array}$ \\
\hline II & $\begin{array}{l}\text { Majority } \\
\text { of } \\
\text { Businesses }\end{array}$ & Adaptation & Productive & $\begin{array}{c}\text { Raw } \\
\text { Materials }\end{array}$ & $\begin{array}{l}\text { NFD2 } \\
\text { STIL1 } \\
\text { HBG1 } \\
\text { AL1 } 1 \\
\text { HUCH1 } \\
\text { IF I } \\
\end{array}$ \\
\hline \multicolumn{2}{|c|}{ II G Government } & Integration & $\begin{array}{l}\text { Managerial// } \\
\text { Political }\end{array}$ & $\begin{array}{c}\text { Contact } \\
\text { with } \\
\text { Influentials }\end{array}$ & $\begin{array}{l}\text { NFD1 } \\
\text { STIL3 } \\
\text { HBG3 } \\
\text { AL3 } \\
\text { HUCH2 } \\
\text { IF3 } \\
\end{array}$ \\
\hline \multicolumn{2}{|c|}{ IV Social Services } & $\begin{array}{c}\text { Latent } \\
\text { Pattern } \\
\text { Maintenance }\end{array}$ & Maintenance & $\begin{array}{l}\text { People \& } \\
\text { Clients }\end{array}$ & $\begin{array}{l}\text { NFD3 } \\
\text { STIL2 } \\
\text { HBG2 } \\
\text { AL2 } \\
\text { HUCH4 } \\
\text { IF2 } \\
\end{array}$ \\
\hline
\end{tabular}

RULE 1: The majority of the SOCIAL SERVICE ORGANIZATIONS go in block four.

$$
\begin{array}{lllll}
1 & \star & \star & \star & \star \\
2 & \star & \star & \star & \star \\
3 & \star & \star & \star & \star \\
4 & \times & \times & \times & x
\end{array}
$$

In the PARSONIAN partitioning, this block contains LATENCY-type organizations. In the KATZ AND KAHN partitioning, this block contains MAINTENANCE organizations. In the RESOURCE DEPENDENCE partitioning, this 
block contains organizations which have PERSONNEL/CLIENTS as their key resource. In the date-driven partitioning, this corresponds to BLOCK 2 in Stilwater (STIL), Hibbing (HBG), Albert Lea (AL), and International Falls (IF). It corresponds to BLOCK 3 in Northfield (NFD), and to BLOCK 4 in Hutchinson (HUCH).

RULE 2: The majority of local GOVERNMENT ORGANIZATIONS go in block three.

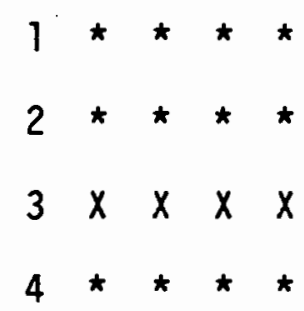

In the PARSONIAN partitioning, this block contains INTEGRATION-type organizations. In the KATZ AND KAHN partitioning, this block contains MANAGERIAL/POLITICAL organizations. In the RESOURCE DEPENDENCE partitioning, this block contains organizations that have CONTACT WITH INFLUENTIALS as their key resource. In the data-driven partitioning, this corresponds to BLOCK 3 in STIL, HBG, AL, and IF. It corresponds to BLOCK 1 in NFD, and to BLOCK 2 in HUCH.

RULE 3: The majority of the BUSINESS ORGANIZATIONS go in block two.

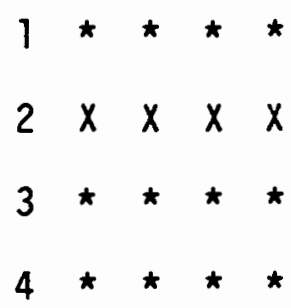

In the PARSONIAN partitioning, this block contains ADAPTATION-type organizations. In the KATZ AND KAHN partitioning, this block contains PRODUCTIVE organizations. In the RESOURCE DEPENDENCE partitioning, this block contains organizations with RAW MATERIALS as their key resource. 
In the data-driven partitioning, this corresponds to BLOCK 1 in STIL, $H B G, A L, H U C H$, and IF. It corresponds to BLOCK 2 in NFD. RULE 4: The majority of the FINANCIAL INSTITUTIONS go in block one.

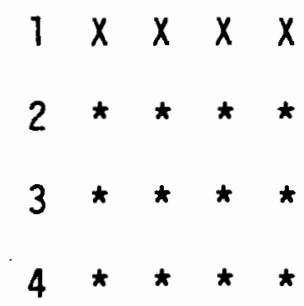

In the PARSONIAN partitioning, this block contains GOAL ATTAINMENT-type organizations. In the KATZ AND KAHN partitioning, financial institutions are included with PRODUCTIVE organizations. Since PRODUCTIVE organizations are already placed in BLOCK 2 (because of DECISION RULE 3), only ADAPTIVE organizations are left to occupy this position. In the RESOURCE DEPENDENCE partitioning, this block contains organizations with MONEY/INFORMATION as their key resource. In the data-driven partitioning, this corresponds to BLOCK 4 in NFD, STIL, HBG, $A L$, and IF. It corresponds to BLOCK 3 in $\mathrm{HUCH}$. 


\section{APPENDIX B}

\section{"b" STATISTIC VALUES}


TABLE XVII

"b" STATISTIC VALUES FOR IMAGE MATRIX I IN EACH COMMUNITY STUDIED

\begin{tabular}{lcccccc} 
PARTITIONING & NFD & STIL & HBG & AL & HUCH & IF \\
\hline DATA-DRIVEN & .181 & .224 & .318 & .315 & .149 & .172 \\
\hline PARSONIAN & .201 & .210 & .255 & .278 & .211 & .131 \\
\hline KATZ \& KAHN & .182 & .185 & .189 & .121 & .089 & .143 \\
\hline $\begin{array}{l}\text { RESOURCE } \\
\text { DEPENDENCE }\end{array}$ & .221 & .248 & .289 & .239 & .206 & .172 \\
\hline
\end{tabular}

TABLE XVIII

"b" STATISTIC VALUES FOR IMAGE MATRIX II IN EACH COMMUNITY STUDIED

\begin{tabular}{lcccccc} 
PARTITIONING & NFD & STIL & HBG & AL & HUCH & IF \\
\hline DATA-DRIVEN & .274 & .170 & .392 & .272 & .148 & .234 \\
\hline PARSONIAN & .349 & .155 & .301 & .258 & .266 & .135 \\
\hline KATZ \& KAHN & .170 & .183 & .227 & .137 & .189 & .149 \\
\hline $\begin{array}{l}\text { RESOURCE } \\
\text { OEPENDENCE }\end{array}$ & .313 & .236 & .391 & .174 & .213 & .207 \\
\hline
\end{tabular}


TABLE XIX

"b" STATISTIC VALUES FOR IMAGE MATRIX III IN EACH COMMUNITY STUDIED

\begin{tabular}{lcccccc} 
PARTITIONING & NFO & STIL & HBG & AL & HUCH & IF \\
\hline DATA-DRIVEN & .275 & .301 & .171 & .279 & .138 & .165 \\
\hline PARSONIAN & .204 & .313 & .239 & .346 & .273 & .235 \\
\hline KATZ \& KAHN & .176 & .457 & .193 & .463 & .129 & .242 \\
\hline $\begin{array}{l}\text { RESOURCE } \\
\text { DEPENDENCE }\end{array}$ & .230 & .388 & .226 & .372 & .203 & .245 \\
\hline
\end{tabular}

TABLE $X X$

"b" STATISTIC VALUES FOR IMAGE MATRIX IV IN EACH COMMUNITY STUDIED

\begin{tabular}{lcccccc} 
PARTITIONING & NFD & STIL & HBG & AL & HUCH & IF \\
\hline DATA-DRIVEN & .299 & .294 & .299 & .354 & .320 & .231 \\
\hline PARSONIAN & .347 & .272 & .272 & .350 & .299 & .247 \\
\hline KATZ \& KAHN & .202 & .245 & .235 & .373 & .287 & .196 \\
\hline $\begin{array}{l}\text { RESOURCE } \\
\text { DEPENDENCE }\end{array}$ & .382 & .286 & .283 & .356 & .310 & .204 \\
\hline
\end{tabular}


TABLE XXI

"b" STATISTIC VALUES FOR IMAGE MATRIX V IN EACH COMMUNITY STUDIED

\begin{tabular}{lccccccc} 
PARTITIONING & NFD & STIL & HBG & AL & HUCH & IF \\
\hline DATA-DRIVEN & .541 & .254 & .261 & .384 & .347 & .211 \\
\hline PARSONIAN & .440 & .452 & .201 & .311 & .333 & .194 \\
\hline KATZ \& KAHN & .316 & .421 & .211 & .480 & .380 & .194 \\
\hline $\begin{array}{l}\text { RESOURCE } \\
\text { DEPENDENCE }\end{array}$ & .589 & .459 & .222 & .386 & .303 & .168 \\
\hline
\end{tabular}

TABLE XXII

"b" STATISTIC VALUES FOR IMAGE MATRIX VI IN EACH COMMUNITY STUDIED

\begin{tabular}{lcccccc} 
PARTITIONING & NFD & STIL & HBG & AL & HUCH & IF \\
\hline DATA-ORIVEN & .062 & .122 & .153 & .280 & .099 & .095 \\
\hline PARSONIAN & .237 & .066 & .119 & .269 & .132 & .090 \\
\hline KATZ \& KAHN & .226 & .086 & .092 & .335 & .114 & .103 \\
\hline $\begin{array}{l}\text { RESOURCE } \\
\text { DEPENDENCE }\end{array}$ & .230 & .121 & .178 & .305 & .149 & .099 \\
\hline
\end{tabular}


TABLE XXIII

"b" STATISTIC VALUES FOR IMAGE MATRIX VII IN EACH COMMUNITY STUDIED

\begin{tabular}{lllllll} 
PARTITIONING & NFD & STIL & HBG & AL & HUCH & IF \\
\hline DATA-DRIVEN & .183 & .093 & .270 & .295 & .121 & .144 \\
\hline PARSONIAN & .200 & .096 & .269 & .220 & .146 & .188 \\
\hline KATZ \& KAHN & .088 & .078 & .168 & .244 & .216 & .182 \\
\hline $\begin{array}{l}\text { RESOURCE } \\
\text { DEPENDENCE }\end{array}$ & .240 & .101 & .269 & .205 & .162 & .122 \\
\hline
\end{tabular}

